IZA DP No. 7039

The Impact of Non-Parental Child Care on Child Development: Evidence from the Summer Participation "Dip"

Chris M. Herbst

November 2012 


\title{
The Impact of Non-Parental Child Care on Child Development: Evidence from the Summer Participation "Dip"
}

\author{
Chris M. Herbst \\ Arizona State University \\ and IZA \\ Discussion Paper No. 7039 \\ November 2012 \\ IZA \\ P.O. Box 7240 \\ 53072 Bonn \\ Germany \\ Phone: +49-228-3894-0 \\ Fax: +49-228-3894-180 \\ E-mail: iza@iza.org
}

Any opinions expressed here are those of the author(s) and not those of IZA. Research published in this series may include views on policy, but the institute itself takes no institutional policy positions. The IZA research network is committed to the IZA Guiding Principles of Research Integrity.

The Institute for the Study of Labor (IZA) in Bonn is a local and virtual international research center and a place of communication between science, politics and business. IZA is an independent nonprofit organization supported by Deutsche Post Foundation. The center is associated with the University of Bonn and offers a stimulating research environment through its international network, workshops and conferences, data service, project support, research visits and doctoral program. IZA engages in (i) original and internationally competitive research in all fields of labor economics, (ii) development of policy concepts, and (iii) dissemination of research results and concepts to the interested public.

IZA Discussion Papers often represent preliminary work and are circulated to encourage discussion. Citation of such a paper should account for its provisional character. A revised version may be available directly from the author. 


\section{ABSTRACT}

\section{The Impact of Non-Parental Child Care on Child Development: Evidence from the Summer Participation "Dip"1}

Although a large literature examines the effect of non-parental child care on preschool-aged children's cognitive development, few studies deal convincingly with the potential endogeneity of child care choices. Using a panel of infants and toddlers from the Birth cohort of the Early Childhood Longitudinal Study (ECLS-B), this paper attempts to provide causal estimates by leveraging heretofore unrecognized seasonal variation in child care participation. Child assessments in the ECLS-B were conducted on a rolling basis throughout the year, and I use the participation "dip" among those assessed during the summer as the basis for an instrumental variable. The summer participation "dip" is likely to be exogenous because ECLS-B administrators strictly controlled the mechanism by which children were assigned to assessment dates. The OLS results show that children utilizing non-parental arrangements score higher on tests of mental ability, a finding that holds after accounting for individual fixed effects. However, the instrumental variables estimates point to sizeable negative effects of non-parental care. The adverse effects are driven by participation in formal settings, and, contrary to previous research, I find that disadvantaged children do not benefit from exposure to non-parental child care settings.

JEL Classification: J13

Keywords: child care, child development, maternal employment

Corresponding author:

Chris M. Herbst

School of Public Affairs

Arizona State University

411 N. Central Ave., Suite 480

Phoenix, AZ 85004-0687

USA

E-mail: chris.herbst@asu.edu

\footnotetext{
${ }^{1}$ I am grateful to participants at the 2012 meeting of the Association for Public Policy Analysis and Management and Southern Economic Association, as well as Joanna Lucio, Erdal Tekin, Bob Bradley, Greg Duncan, Spiro Maroulis, Anna Johnson, Nikki Forry, Melanie Guldi and Joseph Doyle for helpful comments and suggestions.
} 


\section{Introduction}

Over the past few decades, there has been a sharp increase in the share of U.S. preschoolaged children participating non-parental child care arrangements. Currently, two-thirds of young children regularly attend some form of child care, with the average child spending 32 hours per week in these settings (Laughlin, 2010). Moreover, the transition into non-parental care occurs rapidly after childbirth. According to the NICHD Study of Early Child Care (1997a), the typical child first enters child care at approximately three months. Within the first year of life, 80 percent experience regular participation in non-parental arrangements, and over one-third have at least three distinct caregivers. The most common child care setting for preschool-aged children is relative care (41 percent), followed by center- (23 percent) and family-based (13 percent) arrangements (Laughlin, 2010).

Catalyzed by the finding that early childhood health (e.g., Almond \& Currie, 2010; Case et al., 2005) and educational experiences (e.g., Heckman \& Materov, 2007; Karoly et al., 2005) may have lasting effects on schooling and labor market success, developmental psychologists and economists have devoted significant attention to studying the impact of various child care arrangements on child development. Recent work examines a variety of outcomes, ranging from the incidence of injury and infectious disease to cognitive and social-emotional functioning. Although results from this work are quite mixed overall, two themes consistently emerge (Bradley \& Vandell, 2007; Pianta et al., 2009). First, participation in center-based care has opposing effects child development, producing small improvements in mental ability test scores while increasing behavior problems. Second, higher-quality settings produce more favorable short- and long-run outcomes, especially for economically disadvantaged children.

An important concern with much of this research is the insufficient attention paid to the potential endogeneity of child care choices. Families using non-parental arrangements are likely to differ from those that do not in ways that cannot be fully accounted for even in richly specified child production functions. If these unobserved differences are correlated with measures of child 
development, a classic case of omitted variable bias arises, in which the estimated effect of nonparental care is confounded. To date, only a small number of U.S. studies attempt to handle these identification issues. One paper makes use of value-added specifications (NICHD ECCRN \& Duncan, 2003), another three use fixed effects (Blau, 1999; Currie \& Hotz, 2004; Gordon et al., 2007), and one implements an instrumental variables strategy (Bernal \& Keane, 2011). ${ }^{2}$ The latter paper is noteworthy because it finds that increased child care time during the preschool years reduces mental ability test scores, a result at odds with much of the OLS literature. Therefore, considerable uncertainty remains over the implications of non-parental child care utilization for children's development.

Using a panel of infants and toddlers from the Birth cohort of the Early Childhood Longitudinal Study (ECLS-B), this paper provides new evidence on the impact of non-parental child care utilization on mental ability test scores. To distinguish between short- and longer-run effects, the analysis considers two measures of child care utilization. It begins by examining an indicator of current participation in any non-parental arrangement, followed by finer comparisons of formal and informal arrangements as well as relative, non-relative, and center-based settings. It then focuses on cumulative child care utilization, defined as the number of months a given focal child participated in non-parental arrangements at each assessment point. The primary contribution of the paper is the use of a novel empirical strategy to estimate the causal effect of non-parental care. Specifically, it exploits heretofore unrecognized seasonal patterns in child care utilization to provide identifying variation. During the first two waves of the ECLS-B, parental interviews and child assessments were conducted on a rolling basis throughout the year, and I use the child care participation “dip” that occurred among those assessed during the summer as the basis for an instrumental variable. The

\footnotetext{
${ }^{2}$ Note that these papers explore the first-order question of the impact of various non-parental child care arrangements on child development. This topic is distinct from, although related to, the second-order question of the impact of various child care and early education policies (e.g., Child Care and Development Fund, Head Start, and pre-kindergarten) on child development. Generally speaking, obtaining credible identification strategies has been more difficult for studies pursuing the former question than the latter.
} 
estimated summer-induced drop in utilization is strong in the first-stage equation, and it pervades most demographic sub-groups, including working and non-working mothers.

I argue that the timing of ECLS-B assessments generates exogenous variation in child care utilization because parents were not given the opportunity to choose an assessment date. Instead, since the survey was designed to document age-specific developmental milestones, ECLS-B administrators assigned parents to interview dates based on the focal child's birthday. Interviews for the first wave were initiated at the child's 9-month birthday, while those for the second wave occurred at 24- months. I show that families overwhelmingly complied with this assignment rule, and I provide evidence that families interviewed during the summer are observationally equivalent to their counterparts interviewed during other times of the year. Importantly, there is no indication that parents' employment status differs across the summer and non-summer months, nor is there evidence of seasonality in the demand for child care quality, underlying child health, or maternal mental health. Given that the assignment mechanism is based on the focal child's birthday, one concern is that unobserved family differences associated with season-of-birth might invalidate the summer assessment instrument. Indeed, Buckles and Hungerman (2010) document strong seasonal patterns in the socioeconomic characteristics of women giving birth throughout the year. Fortunately, the identification strategy does not require quarter-of-birth to be excluded from the child production function, and the instrumental variables estimates are robust to the inclusion of such controls.

The paper's main findings can be summarized as follows. I first show that children attending non-parental care are more economically advantaged than their peers in parent care. This positive selection suggests that OLS estimates of child care utilization are likely to be biased upward. I then recreate the standard OLS result in the literature that children attending non-parental care score higher on tests of early mental ability, a result that holds when I account for individual fixed effects. However, the instrumental variables estimates point to sizeable negative effects of non-parental child care utilization. For example, baseline results for the measure of current child care participation 
suggest that ability test scores are 8.5 percent to 9.5 percent lower for children in non-parental settings, corresponding to an effect size of approximately 0.29 standard deviations. Contrary to previous research, the negative effects are driven by participation in formal care-including centerbased and non-relative arrangements-and I show that disadvantaged children do not benefit from exposure to non-parental settings.

The remainder of the paper proceeds as follows. The next section summarizes previous research examining the relationship between early non-parental care and child development. Section III introduces the key features of the ECLS-B analysis sample, and Section IV develops the identification strategy. The estimation results are presented in Section V, while Section VI concludes with a discussion of policy implications.

\section{Relevant Literature}

There is a voluminous literature in developmental psychology and, increasingly, economics examining the relationship between non-parental child care arrangements and child development. ${ }^{3}$ The intent here is to provide an overview of the most relevant work, focusing on the short-run effects of infant and toddler care on four of the most heavily studied outcomes: the mother-child relationship, injuries and communicable illnesses, behavior problems, and mental ability.

The early mother-child relationship is widely considered the foundation of children's later psychological and mental development (Collins et al., 2000). ${ }^{4}$ Initial research therefore focused on whether the early and intense use of non-parental care disrupts this relationship (Belsky \& Steinberg, 1978). For example, it is possible that prolonged separation limits mothers' ability respond sensitively to the child, while reducing the child's confidence in the availability and consistency of maternal responsiveness. The most recent empirical evidence indicates that routine non-parental care,

\footnotetext{
${ }^{3}$ Comprehensive reviews are found in Bernal and Keane (2011), Bradley and Vandell (2007), and Pianta et al. (2009).

${ }^{4}$ Indeed, a range of parenting practices from spanking and psychological aggression to the level of maternal sensitivity are found to directly influence children's cognitive and behavioral well-being (Gershoff, 2002; Ispa et al., 2002).
} 
particularly in the first year of life, is associated with elevated rates of attachment insecurity (NICHD ECCRN, 1997b; 2001a) and reduced maternal sensitivity (NICHD ECCRN, 1999).

Previous work also explores the link between non-parental care and rates of injury and communicable illnesses. It is conceivable that early entry into child care, especially settings with large group sizes, increases the likelihood of exposure to pathogens carried by other children. The net effect of prolonged child care exposure could be zero, however, as children beginning non-parental care early in life might develop immunities that prevent the onset of illness during the school-age years. Nevertheless, given the large social costs of treating early childhood injury and illness (Auinger et al., 2003), and the potential long-term impact of early health status (Case et al., 2002), a number of studies examine whether certain child care arrangements are responsible for catalyzing adverse health events. This work consistently finds that time spent in center-based, and to a lesser extent family-based, settings is associated with a greater risk of contracting respiratory and ear infections but not with incurring serious injuries (Gordon et al., 2007; NICHD ECCRN 2001b; 2003a). These effects largely disappear by the time children reach 36-months-indicative of the immunizing effects of early exposure-and there are no detectable spillovers to other areas of child development.

The third domain of research considers children's behavioral development, including positive peer interactions, self-control, and compliance. Such skills are critical to early school achievement and are shown to have long-run implications for mental and behavioral functioning (Raver, 2002). Results from the NICHD ECCRN (1998; 2001c; 2003b) reveal that non-parental care is associated with poorer peer interactions and increased behavior problems, with earlier entry and more intense exposure magnifying the negative effects and higher-quality settings mollifying them. Greater exposure to center-based care in particular increases early disruptive behavior that persists throughout childhood (Belsky et al., 2007). Similar results are evident in other U.S. datasets, including the National Longitudinal Survey of Youth (NLSY) (Bernal \& Keane, 2011). 
The most relevant cluster of research focuses on the implications of early non-parental care for children's mental development. Overall, results from this work tend to find beneficial effects of child care exposure (NICHD ECCRN, 2000), although some uncover neutral (Blau, 1999) or negative effects (Bernal \& Keane, 2011; NICHD ECCRN, 2004). There is a growing consensus, however, that high-quality center-based settings produce favorable results (Hill et al., 2002; NICHD ECCRN \& Duncan, 2003; Peisner-Feinberg et al., 2001), especially when child care teachers engage in cognitively stimulating interactions with children (NICHD ECCRN, 2000). The positive effects of early center-based care tend to be larger for economically disadvantaged children (Loeb et al., 2004), and they are found to persist throughout the school-aged years (Belsky et al., 2007).

Despite this extensive literature, most papers do not deal adequately with the potential endogeneity of child care choices. The most common strategy is to estimate the child production function using ordinary least squares (OLS) regression, conditioning on a rich set of observable family characteristics. However, OLS estimates of child care utilization may still be inconsistent because families using child care may differ from those that do not in ways that are difficult to capture. For example, families using non-parental care may have stronger work preferences, face fewer constraints on obtaining work and child care, or place a higher value on socializing children at an early age. In addition, children exposed to non-parental care may have qualities that parents wish to enhance (e.g., high mental ability) or ameliorate (e.g., disabilities). In other words, child wellbeing could itself be a determinant of parental child care decisions. Failure to account for these systematic differences across families and children will yield inconsistent estimates of the impact of non-parental child care utilization.

To my knowledge, only a few studies attempt to handle these identification problems. One paper makes use of value-added specifications (NICHD ECCRN \& Duncan, 2003), another three use fixed effects (Blau, 1999; Currie \& Hotz, 2004; Gordon et al., 2007), and one implements an 
instrumental variables (IV) strategy (Bernal \& Keane, 2011). ${ }^{5}$ Identification in value-added models is achieved by conditioning on pre-child-care-use (or lagged) mental ability, which is assumed to capture the child's ability endowment as well as unobserved historical inputs. However, as Todd and Wolpin (2003) show, endogeneity problems arise when lagged mental ability is correlated with the unobserved contemporaneous determinants of ability. ${ }^{6}$ The primary advantage of the individual fixed effects model is that it compares a child's mental ability in periods of child care exposure with the ability of the same child in periods of non-exposure. Although this within-child estimator accounts for time-invariant unobservables, a concern is that omitted time-varying inputs will still lead to inconsistent estimates.

The paper by Bernal and Keane (2011) represents the only other attempt to use IV methods in the child care-child development literature. The identification strategy uses 78 social policy variables (e.g., welfare reform rules) to instrument for child care time in a sample of single mothers from the NLSY. The paper's main finding is that each year of child care exposure reduces preschool-aged children's mental ability test scores by 2.1 percent, with participation in informal care driving the negative effects. Although the policy instruments are reasonably powerful in the first-stage equation $(F=14.7)$, it is possible that many of them are related to child development beyond their correlation with child care time, thus potentially invalidating them as instruments. ${ }^{7}$ Another concern is that the measure of child care time is derived from mothers' employment history, making it difficult to

\footnotetext{
${ }^{5}$ The claim that only one other child care paper utilizes an IV strategy should not be confused with the work of Gelbach (2002) and Herbst and Tekin (2010a; 2012). Gelbach instruments for kindergarten attendance, not child care arrangements per se, and explores maternal employment as the outcome. The Herbst and Tekin papers instrument for child care subsidy receipt, again not arrangements per se, but they do examine various measures of child health and development. The paper by Bernal and Keane (2011) represents the only other attempt to instrument for preschool non-parental child care arrangements, a task made very difficult because of a death of variation in child care decisions that is not correlated with maternal employment decisions.

${ }^{6}$ For example, parents in the current period may engage in optimizing behavior in response to child well-being in previous periods.

${ }^{7}$ For example, one of the authors' instruments, state-level child enforcement expenditures, is likely to change the behavior of children's biological fathers in ways that affect child well-being (e.g., through increased time investments). Welfare policies such as child-ageexemptions from work requirements may influence women's fertility decisions, and therefore optimizing behavior regarding qualityquantity trade-offs in maternal investments. Moreover, welfare work requirements and time limits can conceivably influence family wellbeing in ways that are unrelated to child care and work decisions (e.g., through changes in the home environment). Finally, local labor market conditions are known to affect individual health through non-labor-market mechanisms (e.g., through changes in consumption and health-related behaviors).
} 
separately identify the impact of child care exposure and maternal employment. ${ }^{8}$ The current paper builds on Bernal and Keane (2011) by introducing a new instrument to produce credible estimates of the impact of non-parental child care arrangements. The strategy developed here is advantageous because it exploits the ECLS-B's birthday-based assessment schedule, a design feature that is replicated in other surveys of children's early child care experiences (e.g., Fragile Families and Child Well-Being Study). Thus, future work can exploit this identification strategy to examine other child development outcomes.

\section{Data}

Data for this research are drawn from the Birth cohort of the Early Childhood Longitudinal Study (ECLS-B), a nationally representative sample of approximately 11,000 children born in $2001 .^{9}$ The survey was designed to track children's early home and educational experiences by conducting detailed parent and child care provider interviews and initiating a battery of child assessments at various points between birth and kindergarten entry. The first wave of data collection occurred when focal children were 9-months-old (2001-2002), with follow-up surveys implemented at 24-months (2003), during the preschool year (2005-2006), and after kindergarten entry (2006-2007).

The analysis sample is a panel of children from the 9- and 24-month waves of data collection, during which direct child assessments were administered and parents completed detailed questionnaires. In particular, trained interviewers conducted a home visit on or near the focal child's 9- and 24-month birthday. The home visit consisted of child mental and psychomotor assessments and a 60-minute parent interview to ascertain information about demographic and labor market

\footnotetext{
${ }^{8}$ Indeed, one of the reasons the authors are able to leverage reasonably good explanatory power in the first-stage is that the measure of child care time is closely linked to maternal employment, and polices such welfare reform and the EITC have had large effects on single mothers' employment. This is problematic because early maternal employment itself has implications for child development (BrooksGunn et al., 2002; Ruhm, 2004; Morrill, 2011).

${ }^{9}$ Children were sampled from birth registers from the National Center for Health Statistics (NCHS) vital statistics system. Births were sampled within a set of primary sampling units (PSUs) as well as secondary sampling units (SSUs). The original sample included approximately 14,000 births, 10,688 of whom had a completed assessment at the 9-month wave of data collection. The sampling frame included all births, with the following exceptions: children born to mothers less than 15 years-old; children who died prior to the 9-month assessment; and children who were adopted prior to the 9-month assessment. Several groups were oversampled, including low birth weight children, twins, and Native American children.
} 
characteristics, the home environment, child and family health, and current child care utilization. ${ }^{10}$ Exclusions from the sample are made if a child is missing information on the month-of-assessment $(1,930)$ or the type of non-parental child care utilized (30). I retain children with at least one nonmissing mental ability test score from the 9- and 24-month assessments. The result is an unbalanced panel of 10,477 children, providing 19,416 child-wave combinations.

The primary outcome is a measure of children's early mental ability from the Bayley Short Form-Research Edition (BSF-R) test. This instrument was designed specifically for the ECLS-B and includes a subset of items from the full Bayley Scales of Infant Development-Second Edition (BSID-II), a widely used measure of mental development from birth to preschool. Although the original 178-item BSID-II was designed to be completed in a clinical setting, the BSF-R was developed for ease of administration and completion in a home environment. The abbreviated 9- and 24-month BSF-R contains 31 and 33 mental items, respectively. The test assesses several dimensions of early cognitive and language ability, including memory, preverbal communication, expressive and receptive vocabulary, reasoning and problem solving, and concept attainment. Item response theory (IRT) scale scores are used in the analysis.

This study examines two measures of non-parental child care utilization. To capture the short-run effect of child care, I begin with a measure of current participation in any non-parental arrangement. Specifically, I create a binary indicator that equals unity if a given child receives—at the time of assessment—regular care from relatives (inside or outside the focal child's home), nonrelatives (e.g., friends, neighborhoods, nannies, or family-based care inside or outside the focal child's home), and center-based services (e.g., nursery or preschools, for-profit centers, or non-profit church organizations). Auxiliary analyses explore more nuanced measures of child care settings, in particular, by comparing informal and formal child care arrangements as well as relative, non-

\footnotetext{
${ }^{10}$ As stated in the text, parental interviews and child assessments were conducted at the same time during the home visit. For expositional ease, I will hereafter refer only to "child assessments" when discussing the bundle of family activities carried out by ECLS$\mathrm{B}$ administrators during the home visit.
} 
relative, and center-based settings. ${ }^{11} \mathrm{I}$ then examine the longer-run effect of child care by constructing a measure of cumulative participation in all non-parental arrangements, defined as the total number of months of participation at each assessment date. To construct this measure, I combine information on the age (in months) at which focal children began their first child care spell with information on contemporaneous participation at the 9- and 24-month surveys.

The child production function also includes a rich set of child and family characteristics that may be correlated with non-parental child care decisions and children's mental ability. The vector of child controls includes gender, age (up to a quartic polynomial), race and ethnicity (four dummy variables), low birth weight (one dummy variable), premature birth (one dummy variable), and weight (in kilograms). Parental skill and time inputs are proxied by mother's age (up to a squared polynomial), marital status (four dummy variables), maternal education (three dummy variables), the presence of other children in the household (three dummy variables), maternal employment status (three dummy variables), total household income (12 dummy variables), and urban residence (one dummy variable). ${ }^{12}$ The model also includes state fixed effects.

Table 1 presents summary statistics for the analysis sample. Not surprisingly, the average score on the BSF-R increases substantially from the 9- to the 24-month assessment (74.8 versus 125.5). Children receiving non-parental care at 9-months score one-point higher than their counterparts in parent care, a test score gap that grows to approximately two-points by the 24-month assessment. Tests of the null hypothesis of no test score differences are easily rejected at both assessment points. Children in non-parental and parental care are equally likely to be male, white, and classified as low birth weight or premature. However, a number of differences emerge across the family characteristics. In particular, there is consistent evidence that children attending non-parental

\footnotetext{
${ }^{11}$ Informal settings include relative care in any home and non-relative care in the focal child's home. Formal settings are defined as nonrelative care outside the child's home (i.e., family-based services) and all forms of center-based care. In all cases, the omitted category includes children in parent care.

${ }^{12}$ Missing data on child and family variables are retained by imputing zeroes for the missing values and creating dummy variables (that equal unity for the missing data) to account for the possibility of non-random imputation.
} 
care are more advantaged than their peers in parent care. The former group is less likely to have mothers who did not complete high school and more likely to have mothers who completed at least a bachelor's degree. Maternal employment rates are considerably higher among children attending non-parental care, and household income is approximately 25 percent greater, on average. In addition, children attending non-parental care are more likely to be an only-child, whereas those in parent care are more likely to have three or more siblings (14.7 percent versus 8.1 percent, respectively). Such comparisons are useful because they indicate the potential direction of the OLS bias in the estimated effect of non-parental care. In particular, it appears that children receiving nonparental care are positively selected, suggesting that the OLS estimates are biased upward.

Table 2 provides information on children's participation in non-parental arrangements over the infant and toddler years. Panel A shows the participation rate and weekly hours of participation for the measure of current non-parental child care utilization; Panel B provides this information disaggregated by informal and formal care; and Panel C shows data on cumulative participation. Consistent with previous work, children in the ECLS-B experience intensive non-parental care early in life: nearly half spend time in any arrangement as of the 9- and 24-month assessments, and they are engaged in these settings for approximately 33 hours per week. The use of informal care becomes less common as children age, while formal care becomes more common. Approximately 19 percent of children experience a formal non-parental arrangement at 9-months, rising to 27 percent at 24months. The increased reliance on formal care is largely driven by growing participation in centerbased settings. Finally, Table 2 shows that children accumulate about four months of child care exposure by their 9-month birthday, and 11 months of exposure by their 24-month birthday.

\section{Empirical Framework}

\section{Basic Estimation Strategy: OLS and Individual Fixed Effects Models}

The empirical models described below are based on the Becker (1965) and Leibowitz (1974) theoretical frameworks in which the household is assumed to be a productive unit that makes 
decisions about the allocation of time and material resources. These decisions are aimed at maximizing a household utility function of the form $U\left(T, A, G ; x_{1}, x_{2}, \ldots, x_{n}\right)$, where $T$ represents maternal time in leisure; $A$ is a latent measure of child quality (or ability); $G$ captures a set of goods and services that enhance family well-being; and $x$ is a series of exogenous preference shifters. This study is concerned with the estimation of the household demand for child quality, $A$, which, in its most general form, can be specified through the following cognitive ability production function:

$$
A_{\text {it }}=\beta_{1} T_{\text {it }}+\beta_{2} C_{\text {it }}+\beta_{3} G_{\text {it }}+\mathbf{Z}^{\prime} \beta+\mu_{\text {it, }} \text { where }
$$

$T$ represents maternal time inputs (parental child care) for the ith child in each period, $t$; $C$ is a measure of time spent outside of maternal care (non-parental child care); $\mathbf{Z}^{\prime}$ is a matrix of observable child and family characteristics related to the child's ability endowment; and $\mu$ captures the unobserved time invariant and time varying determinants of child ability. Note that maternal and non-maternal time inputs, $T$ and $C$, could enter the production function multiplicatively with quality, such that the contribution of maternal and non-maternal time depends on the quality of that time.

As others note, a number of data and conceptual challenges make it infeasible to estimate equation (1) in practice (e.g., Bernal \& Keane, 2011; Todd \& Wolpin, 2007). First, the inputs to child ability are assumed to be measured in each period, and are thought to have period-specific effects on the development pathway. To avoid the large number of variables necessary to support such a model, most papers in the child development literature make the simplifying assumption inputs have contemporaneous or cumulative effects on child ability. Another challenge is that maternal and nonmaternal time inputs are not measured directly in most survey datasets. ${ }^{13}$ A common approach is to proxy for missing time inputs using indicator variables for maternal employment and non-parental child care utilization. Such controls, however, do not account for the level of quality in maternal and non-maternal time. Indeed, data exigencies preclude measuring the amount of time mothers spend

\footnotetext{
${ }^{13}$ It is also the case $G$ (e.g., the number of books in the home, access to cognitively stimulating toys and activities, access to and type of health insurance, and access to healthy food) are not observed directly in most survey datasets. To sidestep the problem, most studies enter household income into the production function. This variable is problematic for at least two reasons. First, it is endogenous. Second, it is a function of $T$ and $C$, making it difficult to distinguish between the contribution of time inputs and material investments.
} 
reading to the child or observing the quality of teacher-child interactions within the child care environment. Therefore, represented by $\beta_{1}$ and $\beta_{2}$ are the commingled effects of the quantity and quality of maternal and non-maternal time, respectively. Finally, using OLS regression will produce inconsistent estimates of the child production function if the unobserved determinants of ability are correlated with the time and goods inputs. Two sources of unobserved heterogeneity are of concern: time invariant (e.g., environmental conditions at birth) and time varying (e.g., household income shocks) unobservables. Most studies attempt to surmount the omitted variables problem by incorporating a rich set of observable child and family characteristics in $\mathbf{Z}^{\prime}$.

Circumventing these data constraints leads to an estimable version of the baseline child production function:

(2) $\ln \left(A_{\text {its }}\right)=\alpha_{\mathrm{t}}+\beta_{1} N P_{\text {its }}+\mathbf{Z}^{\prime} \beta+v_{\mathrm{s}}+\mu_{\text {its }}$, where

$i$ indexes children, $t$ indexes time (i.e., survey wave), and $s$ indexes state of residence; $\ln (A)$, the natural logarithm of the child's BSF-R score, is a proxy for latent mental ability; $\alpha$ is a binary indicator that captures general time effects or survey design differences between the 9- and 24-month assessment; NP is either the binary indictor of current non-parental child care utilization or the continuous measure of cumulative participation; $\mathbf{Z}^{\prime}$ is a matrix of observable child and family determinants of mental ability; $v$ is a set of state fixed effects aimed at capturing permanent economic, policy, and cultural differences across jurisdictions that may influence child ability; and $\mu$ represents the unobserved time invariant and time varying components of ability. The model also includes interactions between the survey wave indicator, $\alpha$, and two sets of variables: the family inputs in $\mathbf{Z}^{\prime}$ and the state fixed effects. The interactions allow for the possibility that contemporaneous family and environmental inputs have different effects on child ability at each assessment point.

The model specified in equation (2) is estimated on the panel of ECLS-B children using OLS regression. For the binary measure of $N P$, the coefficient of interest, $\beta_{1}$, provides an estimate of the 
average difference in BSF-R scores between infants and toddlers participating in non-parental child care and those using parent care. Given that $\beta_{1}$ is derived from relating BSF-R scores at time $t$ to child care utilization in the same period, the estimate may be interpreted as the short-run effect of participating in non-parental arrangements. It should be noted, however, that children observed using non-parental care at $t$ are likely to have started their spells at different ages, thus leading to different time horizons over which the child care effects can manifest. Nevertheless, to explicitly unpack the longer-run implications of child care utilization, $N P$ is also specified as cumulative participation, in which case $\beta_{1}$ is interpreted as the estimated effect on BSF-R scores of an additional month in nonparental child care settings.

The coefficient $\beta_{1}$ in equation (2) is identified through a cross-sectional comparison of BSFR scores between children utilizing non-parental and parental care. Although this empirical strategy is the most common in the child development literature, estimates derived from this model are likely to be inconsistent because of the omitted variables problem discussed earlier. Thus, I formulate a more convincing identification strategy by exploiting the panel structure of the ECLS-B and including individual fixed effects in the production function. Formally, the fixed effects model is specified as follows:

$$
\ln \left(A_{\text {its }}\right)=\alpha_{\mathrm{t}}+\beta_{1} N P_{\text {its }}+\mathbf{Z}^{\prime} \beta+\gamma_{\mathrm{i}}+\mu_{\mathrm{its}} \text {, where }
$$

$\gamma$ is a set of child-specific effects. ${ }^{14}$ The key advantage of the fixed effects is that they account for all unobserved, time-invariant child- and family-level characteristics that are correlated with nonparental child care utilization and child ability. Note that $\mathbf{Z}$ ' now includes only time varying inputs because all other determinants of ability are consumed by the fixed effects. The identification of $\beta_{1}$ does not come from cross-sectional comparisons of different children, but rather from comparisons of the same child over time. This method, however, is not without limitations. Importantly, it does not

\footnotetext{
${ }^{14}$ Note that the individual fixed effects replace the state fixed effects in equation (3). This is done because there is very little within-child variation in state-of-residence between the 9- and 24-month assessments. Including the state fixed effects along with the child fixed effects, however, does not dramatically change the results reported here.
} 
eliminate sources of time-varying heterogeneity. It is possible, for example, that parental tastes for work and child care evolve over time, or that parental input choices respond to changes in the child's development pathway. If left unobserved such factors could bias $\beta_{1}$ in the fixed effects model.

\section{Instrumental Variables Strategy}

To deal with the selection problems that arise in equations (2) and (3), an instrumental variables (IV) approach may be appropriate in the absence of a research design that randomly assigns children to parental and non-parental care. The IV method will produce consistent estimates of the impact of non-parental child care utilization if at least one variable is found to satisfy two conditions: (i) it is highly correlated with child care participation, and (ii) it is orthogonal to child ability except through its relationship with child care participation. This paper leverages identifying variation through seasonal patterns in child care utilization, in particular, by exploiting the participation “dip” experienced by focal children assessed during the summer months.

During the first two waves of the ECLS-B, parental questionnaires and child assessments were administered on a rolling basis throughout the year. This interview structure was necessary because ECLS-B administrators sought to assess focal children and inquire about child care participation (among other topics) as close to the 9- and 24-month birthday as possible. ${ }^{15}$ Table 3 provides information on the assessment schedule as well as the number of completed assessments each month. ${ }^{16}$ The 9-month survey commenced in October of 2001 and was finished in December of 2002, while the 24-month survey was administered between January and December of $2003 .{ }^{17}$ A reasonably consistent number of assessments were completed each month, including the summer months, which, for the purposes of this study, are defined as June, July, August, and September. This

\footnotetext{
${ }^{15}$ In contrast, the preschool and kindergarten waves were fielded largely in the fall of children's entry into preschool and kindergarten in order to measure baseline development at the start of each school year and to enable researchers to examine changes in development in the year prior to kindergarten entry.

${ }^{16}$ Although it might be preferable to have data on the precise day-of-assessment, only the month- and year-of-assessment are available in the ECLS-B.

${ }^{17}$ Note that there were 16 assessments conducted in April of 2004. It was learned through personal correspondence with ECLS-B administrators that there are no irregularities associated with these cases. Apparently, these cases were simply late in allowing the interviewers to conduct the 24-month assessment. These cases are retained in the main analyses, although their exclusion does not change the results.
} 
period is chosen to represent the summer months because it coincides with the summer vacation schedule of most U.S. public school systems in the period under investigation (Council of Chief State School Officers, 2002). ${ }^{18}$ Fully 29 states contained school districts that began the 2001-2002 school year in September, and the mandated 180-day school-year indicates that June marked the start of summer vacation for most children. This definition is consistent with other studies comparing child care utilization during the summer and non-summer months (e.g., Capizzano et al., 2002). Therefore, the instrument used in this study is a binary indicator that equals unity if a given 9- or 24-month child assessment was conducted between June and September, and zero if the assessment occurred during a non-summer month. In sensitivity checks, I alter the definition of the instrument to include June through August assessments and July through September assessments. The results are robust to these alternative definitions.

\section{The Summer Child Care Participation “Dip”}

There are several reasons to expect a summer participation “dip” in non-parental care among preschool-aged children. Families are more likely to rearrange work schedules to accommodate vacations and extended trips, especially those with school-aged children for whom school is no longer in session. Teenage siblings_also no longer in school and potentially available to watch younger children at various times throughout day—could be viewed by parents as a mechanism for temporarily reducing child care expenses. In addition, many child care directors and teachers may use the summer months to take their own vacation time. This may be particularly true among informal providers, including babysitters and relatives, as well as family-based workers. As a result, employment in the child care sector overall is likely to contract throughout the summer, leaving parents of preschool-aged children with fewer options outside the home.

\footnotetext{
${ }^{18}$ It is difficult to collect information on schools' start and end dates, as there is typically a range of dates within a state on which schools begin the fall semester. In addition, there is variation across states in the mandated length of the school year, although most states mandate that the year contains 175 to 180 days of instruction. To my knowledge, the best available information on state-level school start and end dates comes from the semi-annual report entitled Key State Education Policies on PK-12 Education produced by the Council of Chief State School Officers.
} 
To my knowledge, only two previous studies compare preschoolers' child care utilization across the summer and non-summer months, and both provide evidence of a summer participation “dip.” Using the National Survey of America's Families, Capizzano et al. (2002) find that participation in center-based programs decreases from 32 percent during the school year to 23 percent in the summer and participation in relative care drops from 33 percent to 27 percent among preschool-aged children of employed mothers. The observed rise in parent care-from 28 percent to 35 percent—almost fully explains these declines. A recent paper by Laughlin (2010), which uses the Survey of Income and Program Participation, confirms this participation “dip” among working mothers, and provides evidence that children of non-working mothers are also less likely to participate in non-parental care. Interestingly, both papers find that the summer-induced drop in child care utilization persists across the distribution of household income.

Seasonal patterns in the child care market are also evident on the supply-side. Figure 1 depicts the trend in the monthly number of child care employees between 1985 and 2012. These data are drawn from the Bureau of Labor Statistics' Current Employment Statistics (CES), an establishment-level survey of non-farm employment and earnings. Although the data show a secular rise in the number of child care employees over the past three decades, there are clear seasonal patterns in employment. The child care sector begins to contract in June of each year, reaching a low in July, before returning to pre-summer employment levels in October. The magnitude of this seasonal pattern is fairly large. Since 2000, for example, child care establishments shed approximately 32,000 workers, on average, between May and June and another 44,000 workers between June and July. These losses represent 9.3 percent of the pre-summer child care workforce. ${ }^{19}$

Seasonality in non-parental child care utilization can be examined formally in the ECLS-B through the following first-stage equation:

\footnotetext{
${ }^{19}$ The reported reduction in the child care workforce is likely to be an underestimate of the true reduction because the BLS's CES survey captures child care employees in the formal market (i.e., center- and family-based workers) and likely misses many workers in the informal market (i.e., relatives and babysitters), who tend to work for under-the-table (cash) payments.
} 


$$
N P_{\text {its }}=\alpha_{\mathrm{t}}+\psi_{1} S U M M E R_{\text {its }}+\mathbf{Z}^{\prime} \beta+v_{\mathrm{s}}+\varepsilon_{\text {its }} \text {, where }
$$

$N P$ is the measure of current or cumulative participation in non-parental child care arrangements; and SUMMER is a binary indicator that equals unity if a given child was assessed (and the corresponding parent was interviewed) during the summer. All other controls are identical to those appearing in equation (2). The model is estimated on the pooled set of child-wave combinations from the 9- and 24-month surveys, and the standard errors are adjusted for within-child clustering.

To conserve space, Table 4 presents the first-stage estimates for the binary indicator of current child care utilization; results for cumulative participation are presented in Table 11 and will be discussed later. Columns (1) through (3) use the broad measure of NP as the dependent variable, while columns (4) and (5) examine the binary indicators of informal and formal child care arrangements, respectively. Column (1) includes the child and family controls, column (2) adds the state fixed effects (with wave interactions), and column (3) adds a control for the child's quarter-ofbirth. ${ }^{20}$ The state fixed effects account primarily for cross-state policy differences regarding school start and end dates that may be correlated with the definition of the SUMMER instrument. Although the model includes up to a quartic polynomial in the focal child's age, the quarter-of-birth control captures unobserved parental preferences for child care arrangements that vary with the focal child's season-of-birth.

It is clear from Table 4 that there are seasonal patterns in non-parental child care utilization. In particular, children assessed during the summer experience a participation “dip” relative to their counterparts interviewed during other times of the year. The coefficient on SUMMER in column (2), which is considered the main first-stage equation, indicates that children assessed during the summer are 2.7 percentage points less likely to participate in any non-parental arrangement. With an Fstatistic of 19.6, the SUMMER instrument is quite strong and should allow for precise estimates of the endogenous variable, $N P$, in the production function. Inclusion of quarter-of-birth does not

\footnotetext{
${ }^{20}$ The quarter-of-birth control is a binary indicator that equals unity if a given child was born in the fourth quarter of 2001.
} 
substantially change the estimated effect of SUMMER, nor is the birth variable statistically significant. The summer participation “dip” is also evident across narrower categorizations of nonparental arrangements. Columns (4) and (5) show that children assessed during the summer are equally less likely to participate in informal and formal arrangements than their counterparts assessed during the non-summer months. ${ }^{21}$ In regressions not reported here, I estimate a version of equation (4) that replaces the single SUMMER instrument with separate month-of-assessment indicators (January is the omitted month). The seasonal pattern in child care utilization is evident in this analysis. All four summer month dummies are negative and statistically significant (the magnitudes range from -0.028 in June to -0.041 in September), while the remaining month-of-assessment dummies are small in magnitude and never statistically significant.

As shown in Appendix Table 1, the summer-induced participation drop pervades most demographic sub-groups. Each row reports the coefficient on SUMMER from equation (4) estimated on different child and parent characteristics. Of particular note is that working and non-working mothers and high- and low-SES families are about equally less likely to use non-parental care if they were interviewed during the summer. The two exceptions are found at the bottom of the table, in which first-stage regressions are estimated by the number of children and number of adults in the household. The coefficient on SUMMER indicates that the participation “dip” exists only among focal children with at least one sibling (as opposed to only-children) and among households with two or more adults. These results seem reasonable in light of the discussion earlier that families with multiple (older) children and adults are more likely to stop purchasing child care in the summer because these individuals may be available to assist parents with the care of young children.

The finding that young children during the summer spend increased time in parental care raises several important questions. First, it is useful to know whether the rise in parental care is offset

\footnotetext{
${ }^{21}$ This pattern holds for (separate) regressions of relative, non-relative, and center-based arrangements (compared to parent care). In particular, the coefficient on SUMMER is negative and highly statistically significant in each model.
} 
by a reduction in maternal employment or other changes in work behavior (e.g., shifting from full- to part-time work, delaying a job search, or working from home). Second, it is important to determine the types of activities in which children are engaged with parents, and in particular, whether parental time investments increase during the summer. Such information will highlight the potential mechanisms through which the summer-driven IV estimates operate. To conserve space, Appendix 1 and Appendix Tables 2 through 4 present detailed evidence on these issues. Briefly, four key findings emerge: (i) mothers interviewed in the summer are equally likely to be employed, to be working fullor part-time, and to be looking for work as their counterparts interviewed during the non-summer months; (ii) the summer-induced reduction in child care use occurs primarily among mothers loosely or not attached to the labor force as well as those with flexible work schedules (i.e., working from home); (iii) time investments in the focal child increase substantially during the summer, as evidenced by the increased frequency of several parent-child activities; and (iv) these investments are made disproportionately by the same families experiencing the largest drops in summer child care utilization. Therefore, the IV estimate of $N P$ should not reflect the commingled effect of simultaneous changes in maternal employment and child care use; rather, the estimate likely operates through increased time investments by mothers with flexible work-family schedules.

\section{The Validity of the Summer Assessment Instrument}

In order for the summer assessment variable to serve as an identifying instrument for nonparental child care utilization, it must be validly excluded from the child production function. The most important concern is the possibility that the timing of ECLS-B assessments is correlated with unobserved child characteristics or parental inputs that determine mental ability. This could have occurred for two reasons. First, ECLS-B administrators assigned families to an assessment month based on specific attributes of the focal child. Second, families selected into an assessment month for reasons that are related to child ability. For example, parents in some occupations might have found it convenient to choose a summer assessment date because work and child care schedules were easier 
to rearrange after the school year ended. Alternatively, others may have requested a non-summer assessment for their child because they were employed in seasonal positions that demanded significant time investments throughout the summer. Regardless, if families systematically sorted into assessment months, and the unobserved factors underlying this sorting are correlated with child care decisions and mental ability, then the summer assessment instrument would be invalidated.

Fortunately, parents in the ECLS-B were not given an opportunity to choose an assessment date. Instead, survey administrators linked the timing of assessments to a specific child characteristic, and I observe this assignment "rule" in the data. Specifically, assessments in the first wave were initiated at the focal child's 9-month birthday, while those in the second wave occurred at the 24month birthday. The survey was structured in this manner to enable the ECLS-B to track age-specific developmental milestones. In principle, as long as parents complied with this assignment rule, the child's age should be the only characteristic related to variation in the timing of assessments. Conditioning on age in the production function would therefore enable the summer assessment variable to serve as a valid instrument. On the other hand, if parents failed to comply with this assignment rule, the child's age may not fully explain the observed assessment date, as convenience and other criteria could have been used to schedule the assessment.

I find that parents overwhelmingly complied with the birthday assignment rule. Fully 71 percent of children during the first wave were assessed in the month immediately prior to, the month of, or the month immediately following the 9-month birthday (i.e., ages 8- to 10-months), and approximately 90 percent of children during the second wave were assessed in the month immediately prior to, the month of, or the month immediately following the 24-month birthday (i.e., ages 23- to 25-months). ${ }^{22}$ Nevertheless, I conduct a number of robustness checks to ensure that

\footnotetext{
${ }^{22}$ In other words, 71 percent of children were between 8.0 and 10.9 months old when they were assessed in the first wave, and 90 percent of children were between 23.0 and 25.9 months old when they were assessed in the second wave. These figures are calculated by comparing the focal child's date-of-birth with the month in which the assessment was conducted. Data on exact date-of-birth are available in the ECLS-B, and this was used to construct the child's age (in chronological decimal months) at the time of assessment. However, data on the exact assessment date are not available; only the month-of-assessment is available. Presenting the figures in this
} 
children assessed outside of these windows do not drive the results. I first add to the production function an explicit control for the amount of "error" in the timing of each focal child's assessment. Assuming that children with a chronological age of exactly 9.0 and 24 months in the first and second waves were assessed on their birthday (and hence there is no error in their assessment date), the error variable is constructed by subtracting these numbers from each child's age-at-assessment. Second, I use this variable to restrict the analysis to children assessed within certain bandwidths of assessment error. Specifically, I conduct an analysis that first omits children assessed one month earlier or later than the 9- or 24-month birthday, followed by an analysis that omits children assessed three months earlier or later than the set of birthdays. The IV results are robust to these specification checks. Consistent with the high compliance rates, I find strong evidence that children and parents interviewed during the summer months are observationally equivalent to their counterparts interviewed during other times of the year. Figure 2 depicts trends in several child characteristics over the 9- and 24-month survey periods, while Figure 3 displays a number of family characteristics. The horizontal axis shows each month-of-assessment, and the vertical axis shows the sample proportion with a given characteristic. None of the figures reveal evidence of strong seasonal patterns in the child and family characteristics, and in particular, there are no discontinuous changes in these characteristics at the beginning and end of the summer period.

Tables 5 and 6 formalize the raw trends through a series of regressions of each characteristic on separate indicators for the months included in SUMMER. Panel A displays the unconditional results, and Panel B conditions on the full set of controls outlined in equation (2). Several observations are noteworthy. First, within a given characteristic, coefficients on the individual

three-month window prevents "penalizing" children whose birthdays are at the beginning (or end) of the month, but who were assessed in the last few (or first few) days of the previous (or next) month. For example, consider two children who-because of their date-ofbirth-were supposed to be assessed on December 1, 2001. One child was assessed one week prior to the 9-month birthday (in lateNovember), while the other child was assessed three weeks after the 9-month birthday (in late-December). Although the former child's assessment was initiated closer to the 9-month birthday, only the latter would be included in an analysis that examined children who were assessed sometime during the month in which they turned 9-months old. In any case, "compliance" rates are still high using the stricter 9- or 24-month definition. Approximately one-third of children in the first wave were assessed sometime during the $9^{\text {th }}$-month (i.e., 9.0 to 9.9 months old), and 39 percent were assessed in the second wave sometime during the $24^{\text {th }}$-month (i.e., 24.0 to 24.9 months old). 
summer month dummies are often positively and negatively signed, suggesting the absence of clear seasonal patterns. In addition, very few of the individual summer dummies are statistically significant, irrespective of whether controls are included: of the 80 individual summer-month coefficients presented, only seven are significantly different from zero. Finally, the F-statistics suggest that in only one case is the set of summer dummies jointly significant (the fraction of families in the bottom SES quintile). However, it becomes insignificant when the full set of controls is added. ${ }^{23}$ As a check on these results, Appendix Tables 5 and 6 reexamine the child and family characteristics separately for families that complied with the birthday assignment rule (i.e., children assessed in the month of the 9- or 24-month birthday) and families that did not comply (i.e., those assessed in a month before or after the 9- or 24-month birthday). The findings once again suggest that having a summer assessment is unrelated to the observable characteristics of children and families. It is also reassuring that the characteristics of non-compliers are uncorrelated with the instrument.

Seasonality in maternal employment deserves special attention. As previously stated, one concern is that the summer-induced reduction in child care utilization catalyzed a series of changes to maternal work behavior. If this is the case, the IV estimates of $N P$ would represent the commingled effect of non-parental care and maternal employment. Appendix Table 2 explores this in detail by estimating regressions of various employment outcomes on the SUMMER instrument as well as the full set of controls in equation (2). Each outcome represents a different work margin. I find no evidence of seasonality in maternal employment at any work margin. The coefficients on SUMMER are small in magnitude and never statistically significant, suggesting that maternal employment rates are consistent across levels of the instrument. In results not reported here, a parallel set of analyses on

\footnotetext{
${ }^{23}$ During the 9-month survey, parents completed a self-administered questionnaire, which included 12 items from the Center for Epidemiologic Studies Depression (CES-D) scale. The CES-D items inquire about the frequency (within the previous week) that respondents felt blue, depressed, and fearful; experienced decreased appetite, were less talkative and unusually bothered by things; among other experiences. I use the CES-D scale to explore seasonality in mental health, and in particular, differences between the summer and non-summer months. Regressions of the CES-D scale on the summer assessment dummies (as well as the full set of controls) reveal no differences in maternal depressive symptoms by month-of-assessment.
} 
fathers' employment shows that work behavior does not vary across the summer and non-summer months. Thus, NP can be interpreted as the estimated effect of child care decisions independent of parental employment decisions.

Another concern deals with the possibility of seasonal differences in the level of child care quality to which focal children are exposed. For example, parental preferences regarding provider characteristics might differ across the summer and non-summer months. It is also possible that providers offer bundles of services and activities that change throughout the year. If seasonality in child care quality corresponds to seasonality in utilization, the IV estimates of NP will confound a quality effect with a participation effect. I examine several things to ensure that this is not the case. First, I find that conditional on using any non-parental arrangement, participation rates in relative, non-relative, and center-based settings are virtually identical across children assessed during the summer and non-summer months. This indicates that parental preferences for different child care modes are stable throughout the year. Second, I examine directly whether various features of child care quality vary between the summer and non-summer months. During the 24-month survey, the ECLS-B conducted interviews with the focal child's primary non-parental caregiver and observed a subset of center- and home-based settings to produce global ratings of structural and process quality. ${ }^{24}$ Together, these data provide rich information on the primary non-parental care environment to which focal children were exposed. Table 7 lists the set of child care characteristics examined here, organized around the global measures of quality (Panel A), attributes of the center director (Panel B), and attributes of the child's caregiver (Panel C). Columns (1) and (2) show the coefficient on SUMMER from regressions of each child care characteristic on the full set of 24-month

\footnotetext{
${ }^{24}$ The observation measures of quality include the Infant/Toddler Environment Rating Scale (ITERS) (Cronbach's alpha: 0.86), the Family Day Care Rating Scale (FDCRS) (Cronbach’s alpha: 0.88), and the Arnett Scale of Caregiver Behavior. The ITERS (29 items) and FDCRS (33 items) are classroom-level assessments of global child care quality, based on structural (e.g., child-teacher ratio) and process (e.g., caregiver interaction) features of the environment. The Arnett Scale assesses the nature of the interaction between a specific caregiver-child pair. These observations were conducted with a subsample of providers selected during the 24-month parent interview and who then completed the director and caregiver interviews. To be eligible for a child care observation, the focal child had to be attending a non-parental arrangement for 10 or more hours per week; had to be attending that arrangement for a 2.5 hour block; had a signed parental permission form; among other criteria.
} 
child and family controls and state fixed effects. ${ }^{25}$ Overall, the estimates reveal few-and, importantly, inconsistent—differences in the quality measures between the summer and non-summer months. Of the 30 SUMMER coefficients presented, only five are significantly different from zero. Thus, the IV estimates of NP should not reflect seasonal differences in the quality and characteristics of the non-parental child care environment.

There is one final concern regarding the validity of the summer assessment instrument. Given that the assignment rule is based on the focal child's birthday, a mechanical relationship exists between the month-of-assessment and season-of-birth. Table 8 depicts this relationship separately for the 9- and 24-month surveys. Not surprisingly, it shows that children assessed in each subsequent summer month were born deeper into 2001. For example, children assessed in June for the 9-month survey were largely born in the second and third quarters of 2001 (92 percent), while those assessed in July were largely born in the third and fourth quarters (84 percent). Children assessed during the final summer month were overwhelmingly born in the fourth quarter (72 percent). The same pattern exists in the 24-month wave. One concern is that unobserved family differences associated with season-of-birth might invalidate the summer assessment instrument. Indeed, Buckles and Hungerman (2010) document strong seasonal patterns in the socioeconomic characteristics of women giving birth throughout the calendar year. Children born in the first quarter are more likely to have teenaged mothers, mothers who are unmarried, and mothers who dropped out of high school. The authors show that seasonality in birth characteristics is explained in part by maternal preferences and anticipated conditions at conception and birth (e.g., weather), many of which are difficult to measure. $^{26}$

\footnotetext{
${ }^{25}$ There are cases in which fairly long gaps exist between the timing of the parental interviews (when child care arrangement data were collected) and the timing of the child care interviews and observations. An obvious concern is that, for example, the parent interview was conducted during the summer, but the child care observation was delayed until after the summer. Therefore, all models include a control for the temporal gap between the parent interview and the child care quality data collection.

${ }^{26}$ The Buckles and Hungerman (2010) paper criticizes the use of season-of-birth as an IV, which was first used by Angrist and Krueger (1991) and used subsequently in several other literatures, including the child care literature (Gelbach, 2002). These studies assume that season-of-birth is uncorrelated with other characteristics that determine schooling or labor market outcomes. See Cascio and Lewis (2006) for another example of a paper expressing skepticism over the use of season-of-birth. As stated in the text, the current paper does
} 
I take a number of steps to ensure that seasonality in birth characteristics does not confound the IV results. Although a correlation exists between the month-of-assessment and season-of-birth, as confirmed in Table 8, the identification strategy does not require quarter-of-birth to be excluded from the child production function. Therefore, I conduct a series of robustness checks that include explicit controls for quarter- and month-of-birth in the production function. I also attempt to control for environmental conditions at childbirth by replacing the contemporaneous state-of-residence fixed effects with state-of-residence-at-birth fixed effects. Finally, I exploit the panel structure of the ECLS-B and estimate IV fixed effects (IV FE) models, which yield within-child estimates of the impact of non-parental child care utilization. Doing so effectively neutralizes concerns over the unobserved between-child differences associated with season-of-birth. As discussed in the next section, the baseline IV estimate is robust to all of these specification checks.

\section{Estimation Results}

\section{OLS and Fixed Effects Estimates for Current Non-Parental Child Care Utilization}

This section discusses results from the OLS and child fixed effects models examining the relationship between current child care utilization and mental ability test scores. As shown in Table 9, the OLS results are presented in columns (1) through (4), while the fixed effects results are presented in columns (5) and (6). Differences across the columns are related to the types of controls added to the production function. Columns (4) and (6) represent the richest OLS and fixed effects specifications, respectively. Each cell displays the coefficient and standard error (in parentheses) on the indicator for non-parental child care utilization.

Looking at the OLS results, the evidence consistently points to a positive association between current non-parental child care utilization and young children's mental ability test scores, a result that is consistent with much of the prior OLS literature. However, it appears that the estimate declines

not use season-of-birth as an IV. However, the IV used here is mechanically related to birth timing, and so similar concerns warrant careful attention to the issues raised by both papers. Among other robustness checks, I follow the general approach taken in Cascio and Lewis (2006) and allow quarter-of-birth to enter the production function. 
substantially as controls are added to the production function. In a model that controls only for survey wave [column (1)], use of any non-parental arrangement is associated with an increase in the BSF-R score of 1.4 percent. This corresponds to an effect size of 0.05 standard deviations. This effect is reduced to a 0.3 percent increase in the BSF-R (0.01 standard deviations) in the richest OLS specification [column (4)]. Overall, the magnitude of the child care effect declines about five-fold moving from the sparsest to the fullest model.

The estimates in columns (5) and (6) account for child fixed effects, an empirical strategy used by only a small number of previous child care studies. Column (5) omits the time-varying child and family controls, while column (6) adds them. In both cases, the estimated effect of non-parental care continues to be positive, statistically significant, and of a magnitude similar to the OLS results. Interestingly, inclusion of the time-varying controls reduces the magnitude of the child care effect by about half, to a 0.4 percent increase in the BSF-R. This underscores the importance of the timevarying determinants of mental ability, and raises the concern that the fixed effects estimator could still be inconsistent if any such factors remain unobserved. It should also be pointed out that the overall pattern of decreasing child care effects (as controls are added) is consistent with the descriptive comparison of participants in parental and non-parental child care. In particular, given that those using non-parental arrangements are positively selected, it is not surprising that the child care coefficient becomes less positive (i.e., approaches zero) as more controls are added to the production function.

\section{Instrumental Variables Estimates for Current Non-Parental Child Care Utilization}

Table 10 reports the reduced form and IV estimates of the impact of current child care utilization. All models include the full set of child and family controls and, unless specified otherwise, the state fixed effects with wave interactions. Column (1) depicts the first-stage estimate of the effect of SUMMER, the instrument, on the endogenous variable, $N P$, the binary indicator of current non-parental child care utilization. Column (2) reports the coefficient from the reduced form 
regression, in which the outcome, BSF-R scores, is regressed on SUMMER. Columns (3) and (4) report the IV estimates for $N P$, while columns (5) and (6) report the IV FE estimates. All of the IV estimates are derived by two-stage least squares (2SLS) regression.

The first-stage estimate differs slightly from that presented in Table 4 because of the sample construction. The initial estimate comes from the full sample of children, including those with missing test score data. The estimate in Table 10 is derived from the sub-set of children with nonmissing test score data, a restriction that drops 345 children from the analysis. Nevertheless, with an F-statistic approaching 18, the SUMMER instrument is highly correlated with NP. The reduced form estimate, reported in column (2), is positive, suggesting that children assessed during the summer score 0.3 percent higher on the BSF-R than children assessed during other times of the year. This estimate is interesting because it provides insight into the direct relationship between being assigned to a summer assessment and early mental ability test scores. The discussion of Appendix Tables 2 through 4 indicates that the mechanism for this reduced form effect is not likely to be through changes in maternal employment. Rather, it appears that mothers with flexible work-family schedules are less likely to use non-parental arrangements in the summer, and are more likely to make high-quality time investments in their children.

Given the negative coefficient on SUMMER in the first-stage equation and its positive coefficient in the reduced form equation, it is not surprising that the IV estimate on NP is negative in the baseline IV regression [column (3)]. The coefficient indicates that infants and toddlers attending non-parental arrangements score 9.4 percent lower on the BSF-R than children in parental care. This result is striking especially when compared to the OLS and fixed effects estimates discussed earlier, all of which imply positive effects of non-parental child care utilization. In addition, this result stands in contrast to the bulk of previous work on this issue. A key exception is the recent paper by Bernal and Keane (2011) — the only other IV paper in the child care-child development literature—which also finds that increased child care time reduces mental ability test scores. The model in column (4) 
is the first of several attempts to account explicitly for the potential seasonality in birth characteristics. The model adds a control for quarter-of-birth, defined as a binary indicator that equals unity if a given child was born in the fourth quarter of $2001 .^{27}$ Adding quarter-of-birth reduces only slightly the estimated effect of non-parental care, to an 8.5 percent reduction in BSF-R scores, and the coefficient remains statistically significant. The IV estimates in columns (3) and (4) both correspond to an effect size of approximately 0.29 standard deviations.

Columns (5) and (6) provide a more rigorous check on the potential implications of seasonality in birth characteristics. The columns represent two versions of an IV FE model that replaces the state fixed effects with individual fixed effects. All other controls are consistent across the IV and IV FE models. Column (5) uses as the instrument the SUMMER variable used in the previous IV regressions. It is reassuring that the point estimate on non-parental care is similar to those from the IV models in columns (3) and (4). The key difference between the two results resides with the standard error, which becomes nearly four times larger in the IV FE regression. Because a non-trivial number of children are assessed in the summer of both the 9- and 24-month surveys, the child fixed effects substantially reduce the amount of (within-child) variation in SUMMER, decreasing the efficiency of the IV FE estimate relative to the baseline IV estimate. One way to improve efficiency is to increase the number of identifying instruments, in this case by replacing the single SUMMER variable with separate indicators for each summer month in which focal children were assessed. Doing so increases the amount of within-child variation in the IVs because those with summer assessments in both waves likely had the assessment completed in different months. Column (6) reports the IV FE results based on this expanded set of four instruments. The coefficient implies a

\footnotetext{
${ }^{27}$ As discussed in the previous section, the SUMMER instrument is fairly highly correlated with the quarter-of-birth dummies. For example, the correlation between SUMMER and the dummy for births in the fourth quarter (QOB-4) is 0.42 . Nevertheless, as shown in Table 4, SUMMER still leverages enough explanatory power in NP to precisely identify its impact on BSF-R scores. The coefficient on QOB-4 in the child production function is positive, albeit small in magnitude, and marginally statistically significant. This result is consistent with previous work which finds that children born in the fourth quarter generally have more positive outcomes (e.g., Buckles \& Hungerman, 2010). In a robustness check, I replace the QOB-4 dummy with a QOB-1 dummy. The results are qualitatively similar to those discussed in the text. The coefficient on QOB-1 is negative and imprecisely estimated.
} 
9.2 percent reduction in BSF-R scores — similar in magnitude to the other IV estimates — and the standard error decreases by nearly two-thirds relative to that reported in column (5). Overall, the results in columns (4) through (6) suggest that unobserved seasonal patterns in birth characteristics are not likely to be problematic in this analysis.

\section{Estimates for Cumulative Non-Parental Child Care Utilization}

The results to this point provide evidence on the short-run impact of non-parental child care utilization. To explore the longer-run effect, Table 11 provides OLS, fixed effects, and IV estimates of NP based on a measure of cumulative child care participation. Columns (1) and (2) show the firststage relationship between the SUMMER instrument and cumulative child care; columns (3) and (4) present the OLS and fixed effects estimates, respectively; and columns (5) and (6) present the IV results.

The first-stage estimates continue to reveal a strong relationship between the timing of ECLS-B assessments and the measure of $N P$, cumulative child care participation. The coefficient on SUMMER in column (1) indicates that children assessed during the summer participate about onehalf fewer months in non-parental arrangements than their counterparts assessed during other times of the year. The F-statistic on SUMMER is over 16, and the inclusion of a control for quarter-of-birth in column (2) does little to diminish the strength of the instrument. Consistent with the measure of current child care utilization, the OLS estimate on cumulative care indicates a positive relationship with mental ability, such that an additional month of non-parental arrangements is associated with a 0.04 percent increase in the BSF-R. Inclusion of the fixed effects increases the magnitude of this positive relationship to a 0.1 percent increase in the BSF-R. Both estimates are highly statistically significant.

The last two columns in Table 11 present the IV estimates for cumulative child care. Column (5) excludes the control for season-of-birth, while column (6) includes it. In both cases, the coefficient on $N P$ is negative, suggesting that a greater number of months in non-parental care 
reduces children's mental ability test scores. In particular, a one-month increase in cumulative child care results in a 0.7 percent to 0.8 percent reduction in the BSF-R. Both IV estimates are statistically significant. Once again, the consistency of the estimates in columns (5) and (6) suggests that unobserved seasonality in birth characteristics is not likely to be biasing the impact of $N P$. Overall, there is remarkable consistency in the results emerging for the measures of current and cumulative child care utilization: the OLS estimates point to small, positive associations between NP and early mental ability; however, once the endogeneity of child care choices is fully accounted for, it appears that more time spent in non-parental child care settings is detrimental to ability.

\section{Robustness Checks}

Table 12 presents results from a battery of specification tests intended to check the robustness of the main IV estimates for current and cumulative child care. The first three rows control for various dimensions of child health that may have a seasonal component and share a correlation with early mental ability. First, if there are underlying seasonal differences in child well-being, one might assume that they would be partially reflected in parents' self-reports of overall child health. Row (1) includes such a control in the model. Second, the controls in rows (2) and (3) account for a number of specific dimensions of child health that potentially exhibit seasonal patterns and that could influence mental ability test scores. In particular, row (2) adds indicators for recent asthma and ear infection diagnoses, while row (3) controls for recent injuries. Inclusion of these additional child health controls does alter the estimated effect of current or cumulative child care.

It is also possible that elements of maternal health and employment exhibit seasonal patterns. Recall the evidence discussed earlier that maternal depressive symptoms do not vary across the summer and non-summer months of the 9-month survey. However, given that the CES-D is not available in the 24-month survey, it cannot be included in the model. Therefore, in row (4), I proxy for underlying maternal physical and mental health by adding a measure of self-reported overall health status. Row (5) adds a set of 23 binary indicators denoting various maternal occupational 
categories. These controls account for the possible correlation between the SUMMER instrument and mothers' occupation. It is plausible, for example, that mothers employed in more flexible occupational sectors, or sectors with reduced summertime hours, may be more likely to schedule their child's assessment during the summer. If these occupational choices are correlated with mental ability, the SUMMER instrument would be invalidated. As shown in Table 12, inclusion of these maternal health and occupation controls does not alter the estimated effect of non-parental child care utilization.

Rows (6) through (8) experiment with other methods of accounting for potential seasonal patterns in child birth characteristics. Row (6) replaces the quarter-of-birth control used in the previous analyses with a month-of-birth indicator that equals unity for births that occurred in January. Row (7) attempts to control for state-level conditions (e.g., weather) that existed at the time of the focal child's birth. It does so by replacing the contemporaneous state fixed effects with stateof-birth fixed effects. Previous work finds that seasonality in birth characteristics is greater in southern states (Lam \& Miron, 1991). Therefore, row (8) estimates the IV model with children residing in the South omitted. These alternative specifications consistently yield IV estimates of current and cumulative child care that are similar to the baseline estimates.

The next four rows [rows (9) through (12)] experiment with alternative definitions of the SUMMER instrument. Row (9) classifies June as a non-summer month instead of a summer month, and row (10) omits from the analysis focal children who were assessed in June during the 9- or 24month survey. Rows (11) and (12) conduct the analogous exercises with September. Across all four alternatives, the coefficient on $N P$ remains negative and statistically significant. It is interesting to note, however, that reclassifying June as a non-summer month leads to a smaller IV estimate (relative to the baseline result), while reclassifying September as a non-summer month leads to a larger estimate.

The final robustness checks in Table 12 appear in rows (13) and (14). Recall that the baseline 
IV model includes controls for maternal employment status and household income. These variables may be problematic, however, as they are likely to be endogenous. Regarding income, it is preferable to omit only those income sources that change as a result of using non-parental child care arrangements. Such information, however, is not available in the ECLS-B. Therefore, I omit total income as well as the measure of maternal employment to assess whether the IV estimate of $N P$ is robust. Exclusion of these controls does not significantly change the estimated child care effects.

In robustness checks not presented here, I address the amount of error in the timing of ECLSB assessments. Recall that although parents largely complied with the ECLS-B's birthday-based assignment rule, compliance was not perfect. In other words, some children were assessed in months before or after that containing the 9- and 24-month birthday. If this error is correlated with the use of non-parental child care arrangements and mental ability, the SUMMER instrument would be invalidated. Therefore, I add to the IV model a binary indicator that equals unity if a given child was assessed in the same month containing the 9- or 24-month birthday, and zero if the child was assessed before or after the birthday month. This variable is an explicit control for the amount of error involved in complying with the assignment rule. In addition, I constrain the analysis sample to children within specified bands of assessment error. I first omit children who were not assessed in the month of the 9- or 24-month birthday, followed by an analysis omitting children who were not assessed within three months of the 9- or 24-month birthday. The IV estimates are robust to these specification and sample changes.

To this point, identification of NP has come from a single instrument, SUMMER. However, as the previous discussion suggests, there are ways to alter the instrument set, for example, by overidentifying the model. Increasing the number of instruments can allow one to examine several things. First, it is useful to determine whether the IV estimates are sensitive to changes in the instrument set. Second, with multiple instruments, one can test the exogeneity of the overidentifying restrictions. Finally, IV estimates from an alternative estimator, limited information maximum likelihood 
(LIML), can be compared to those from the 2SLS estimator. It has been shown that 2SLS estimates tend to be biased toward the OLS estimates as the number of instruments increases (e.g., Bound et al., 1995; Hansen, et al., 2008). LIML, on the other hand, corrects for this many-instruments bias, thereby providing a way to assess the 2SLS estimates.

Table 13 examines these issues in the context of three alternative definitions of the instrument set. Columns (1A) and (1B) construct two instruments: one binary indicator for summer assessments at the 9-month survey and another for summer assessments at 24-months. Columns (2A) and (2B) contain four instruments: one binary indicator for each summer month across the 9- and 24month waves. Finally, columns (3A) and (3B) examine eight instruments: one set of four summermonth indicators for the 9-month wave and another set of four indicators for the 24-month wave. Constraining the analyses to the measure of current child care utilization, several noteworthy findings emerge. First, increasing the number of instruments does not substantially change the 2SLS estimates. As shown in columns (1A), (2A), and (3A), the estimates of $N P$ reside within a narrow range, and are similar the baseline estimate reported in column (3) of Table 10. In addition, the instruments consistently pass the exogeneity test. With p-values of $0.57,0.54$, and 0.21 , Wooldridge Score tests of the null hypothesis that the overidentifying instruments are valid are never rejected. Finally, a general observation is that the 2SLS and LIML estimates tend to be similar, although the LIML estimates are consistently larger, and the difference between the two estimates grows with the number of instruments. This suggests that the 2SLS estimates may represent a lower-bound estimate of the (negative) impact of non-parental child care utilization.

\section{Informal Versus Formal Non-Parental Arrangements}

To this point, the analysis of current child care utilization treats all non-parental arrangements with a single variable. This masks potentially important heterogeneity in the impact of individual child care settings. For example, it is conceivable that formal environments (e.g., centerbased care), in which teachers must meet state-specific education and training requirements, might 
have more favorable effects on the mental development of infants and toddlers. On the other hand, the comparatively large group sizes and higher child-teacher ratios found in centers may weaken the ability of teachers to engage in stimulating interactions with children. Most previous research finds that children attending formal care, especially family- and center-based services, perform better on tests of early mental ability than their counterparts in informal settings.

Table 14 and Appendix Table 7 investigate heterogeneity in short-run child care effects across different non-parental arrangements. Table 14 explores differences across informal and formal providers, while Appendix Table 7 compares relative, non-relative, and center-based care. ${ }^{28}$ Column (1) in both tables shows the OLS results, column (2) adds the fixed effects, and column (3) implements the baseline IV strategy. Consistent with previous OLS studies, Table 14 shows that children attending formal non-parental arrangements score statistically significantly higher on the BSF-R than their counterparts in exclusively parent care, while children in informal arrangements perform no differently from those in parent care. The finer categorization in Appendix Table 7 reveals that center-based care is the most beneficial setting for infants and toddlers. In fact, children in relative and non-relative arrangements perform no differently on the BSF-R from those in parent care. Thus, it appears that the positive effect of any non-parental arrangement discussed earlier is driven almost exclusively by those in formal, center-based child care settings.

The story changes substantially once the fixed effects are introduced. The estimate on formal care becomes smaller and imprecisely estimated, while that of informal care increases threefold and becomes statistically significant. This pattern is also evident in Appendix Table 7: the introduction of fixed effects reduces the coefficient on center-based care, rendering it imprecisely estimated, while the coefficient on relative care more than doubles and becomes statistically significant. There is little change in the coefficient on non-relative care. Such large changes in the estimates deserve careful

\footnotetext{
${ }^{28}$ Recall that informal settings include relative care in any home and non-relative care in the focal child's home. Formal settings are defined as non-relative care outside the child's home (i.e., family-based services) and all forms of center-based care. In all cases, the omitted category includes children in parent care.
} 
attention. One potential explanation is that families using formal care are positively selectedimparting an upward bias on the corresponding OLS estimate-and families using informal care are negatively selected-imparting a downward bias on the corresponding OLS estimate. Once the timeinvariant unobservables are accounted for, the impact of formal care becomes smaller and that of informal becomes larger. ${ }^{29}$

The IV estimates magnify the pattern established by the fixed effects. As shown in Table 14, the sign on informal and formal care flips from positive to negative, but the magnitude of the negative effect is substantially larger for the latter. The IV estimates imply that children currently attending formal care score a precisely estimated 13 percent lower on the BSF-R than their peers in parent care, while those in informal care score an imprecisely estimated five percent lower. The IV results in Appendix Table 7 reveal that children utilizing non-relative and center-based services appear to be driving these negative effects. Indeed, such children are about equally worse off relative to their counterparts in parent care. Children in relative settings also perform worse than those in parent care, but the difference is much smaller in magnitude and not precisely estimated. ${ }^{30}$ To my knowledge, no prior study has found that infants and toddlers attending center-based services perform worse on tests of mental ability than those in virtually every other environment. It is also noteworthy that they stand in contrast with the Bernal and Keane (2011) IV results, which find that the negative impact of overall child care time is driven by time spent in informal arrangements. ${ }^{31}$

\section{Heterogeneous Effects of Non-Parental Child Care Utilization}

The results presented so far assume that non-parental arrangements have homogeneous effects on early mental ability across different sub-groups of children and families. To explore

\footnotetext{
${ }^{29}$ There is some descriptive evidence in the ECLS-B in support of this differential selection. Average household income is substantially higher among children in center-based settings ( $\$ 60,378$ compared to $\$ 47,010$ for children in relative care), as is maternal education levels. Approximately 34 percent of mothers with children in center-based care have a BA degree or higher, compared to 21 percent among those with children in relative care.

${ }^{30}$ As a robustness check, I estimate models that added the control for quarter-of-birth to the informal/formal care models as well as the relative/non-relative/center-based models. The results are consistent with those discussed in the text.

${ }^{31}$ Time in formal services, on the other hand, increases children's test scores, although the authors' estimate is not statistically significant.
} 
possible heterogeneity in short-run child care effects, I estimate the baseline IV model separately on boys and girls, white and non-white children, married and unmarried mothers, and families at the low and high end of the skills and SES distributions. Such analyses are potentially important, given that previous maternal employment and child care studies find significant variation across these subgroups. For example, it appears that economically advantaged children tend to be more adversely affected by early maternal work (Anderson et al., 2003) and child care policy reforms (Herbst \& Tekin, 2010a; 2012). A related stream of research finds that economically disadvantaged children benefit substantially more from early exposure to non-parental care (Loeb et al., 2004).

Table 15 reports results from the sub-group analyses, based on the measure of current child care utilization. Column (1) shows the OLS results, column (2) adds the fixed effects, and column (3) implements the baseline IV strategy. Generally speaking, results from the OLS and fixed effects regressions are consistent with previous studies showing that economically disadvantaged children benefit from exposure to non-parental arrangements, and that these benefits exceed those accruing to advantaged children. In particular, the fixed effects results in column (2) reveal that children of lowskilled mothers and from low-SES families score higher on the BSF-R if they participate in any nonparental arrangement. Furthermore, the magnitude of the positive child care effect is substantially larger than that for the comparable set of advantaged children. The benefits of non-parental care are four times larger for children of mothers with no more than a high school degree than it is for children of mothers with more than a high school education. A similar gap exists between children at the low and high ends of the household SES distribution.

The IV estimates reveal a different story in two respects. First, in no case do I find that nonparental child care utilization has a positive impact on the BSF-R scores of disadvantaged children. In fact, across all sub-sets of disadvantaged children, the coefficient on non-parental care implies lower test scores on average than those in parent care, although the magnitude of the negative effect is small and always imprecisely estimated. Second, exposure to non-parental arrangements among 
advantaged children generates large and statistically significant negative effects on BSF-R scores. In particular, white children, children of married mothers, and children in the top SES quintiles are adversely affected by non-parental child care utilization. In sum, the IV estimates indicate that economically disadvantaged children do not benefit from non-parental arrangements, a result that stands in contrast to most previous research, while advantaged children in such arrangements perform significantly worse than their peers in parent care.

\section{Additional Child Development Outcomes}

During the home visit of the 9- and 24-month surveys, ECLS-B interviewers conducted tests of motor skills with the focal child. These tests, drawn from the BSF-R, included 35 items during the 9-month survey and 32 items during the 24-month survey that tapped various dimensions of fine and gross motor abilities (e.g., picking up objects, stringing beads, and jumping of the floor), perceptualmotor integration (e.g., physical imitation of others' postures), and balance (standing on the right and left foot). I combine these individual items into a unified scale score of motor skills, and estimate OLS, fixed effects, and IV regressions of the log of the motor skills score on the measures of current and cumulative non-parental child care.

As shown in Table 16, the OLS and fixed effects results imply no effect of current nonparental child care utilization on infant and toddler motor skills. This pattern is consistent across the separate indicators of informal and formal arrangements. Nevertheless, all of the OLS and fixed effects estimates are positively signed. However, IV results suggest a large and statistically significant negative effect of non-parental care. The coefficient in Panel A indicates that children currently using such arrangements score 14 percent lower on the test of motor skills than children in parent care. Consistent with the mental ability test results, the models in Panel B show that these negative effects are driven by children's current participation in formal arrangements. In fact, those in informal settings do not appear to be adversely affected relative to their counterparts in parent care. The results for cumulative child care, presented in Panel C, reveal a similar story, with the 
exception that the fixed effects results are negative and statistically significant. The IV results magnify this negative effect, suggesting that each one-month increase in non-parental child care exposure reduces the motor skills scale score by 1.4 percent.

\section{Conclusion}

Using a panel of infants and toddlers from the ECLS-B, this paper estimates the causal effect of current and cumulative non-parental child care utilization by leveraging plausibly exogenous seasonal variation in child care participation. In particular, children assessed during the summer of the 9- and 24-month surveys are less likely to be observed participating in non-parental care, and I use the summer participation "dip” as the basis for an identifying instrument. The participation "dip” is likely to be orthogonal to the unobserved determinants of children's mental ability test scores because ECLS-B administrators controlled the mechanism by which children were assigned to assessment dates. As previously stated, this paper represents only one of two attempts to use IV methods to study the impact of non-parental child care arrangements on the mental ability of preschool-aged children.

The paper's main findings are as follows. I recreate the standard OLS result that children attending non-parental care score higher on the BSF-R, a finding that holds when I account for individual fixed effects. The IV results, however, suggest that the OLS and fixed effects estimates suffer from severe upward bias. In particular, the baseline results suggest that ability test scores are 0.29 standard deviations lower for children currently attending non-parental arrangements. The results for cumulative child care similarly indicate that an additional month in non-parental settings reduces ability test scores by 0.8 percent. I also present evidence that the negative effects are driven by participation in formal care, including center-based and non-relative arrangements. Finally, contrary to previous research, disadvantaged children do not appear to benefit when they are exposed to non-parental arrangements.

These results are important from a public policy perspective. In response to the growing 
reliance on non-parental caregivers, policies to support families and providers have grown in scope, magnitude, and delivery mechanism. Indeed, contemporary early care and education policy is administered through a complex web of direct price subsidies to support parental employment (Child Care and Development Fund, CCDF), tax credits to offset child care expenses (Child and Dependent Care Tax Credit), and provider reimbursements for meals served in family- and center-based environments (Child and Adult Care Food Program). In addition, federal and state governments fund an array of education-based services through Head Start and pre-kindergarten.

The potential impact of these policies and programs on child development has been the subject of growing scholarly interest. Herbst and Tekin (2010a; 2010b; 2012) find that CCDF child care subsidies have negative effects on preschool-aged children, lowering cognitive ability test scores and increasing a variety of behavior problems. On the other hand, studies of Head Start (e.g., Deming, 2009; Ludwig \& Miller, 2007; U.S. Department of Health \& Human Services, 2005; 2010) and pre-kindergarten (e.g., Gormley \& Gayer, 2005; Hustedt et al., 2007; 2008; Wong et al., 2008) produce more favorable cognitive and social-emotional outcomes.

Drawing definitive conclusions from this policy research is complicated because the programs rely on the existing child care market to deliver most of its services. As such, children are exposed to extremely diverse non-parental child care environments with variable health and safety regulations, teacher quality, and resource availability. For example, given that the CCDF is designed to maximize parental choice in selecting child care providers, a large number of subsidized children attend friend and relative arrangements in addition to formal services operating out of child care centers. ${ }^{32}$ Children attending pre-kindergarten also experience a range of settings, many of which are delivered through Head Start and are located in local public schools or for-profit child care centers (Piana et al., 2009). In many respects, the varied care received by children in publicly-subsidized

\footnotetext{
${ }^{32}$ In fact, recent estimates suggest that although subsidized children are served predominantly in licensed center- and family-based settings, nearly one-quarter of recipients attend unregulated informal care (Office of Child Care, 2010).
} 
settings is representative of that within the broader preschool-aged population.

Therefore, it is crucial to produce credible evidence on the first-order question of the impact of these diverse non-parental arrangements on child development. The primary advantage of such evidence is that it will increase policymakers' understanding of the mechanisms through which early care and education policies operate. In particular, the research may help to explain why some policies are found to have seemingly counterintuitive effects on children. Results from previous studies of CCDF child care subsidies are illustrative of this point. Given that child care subsidies are largely used to purchase center-based services, and, as discussed in the literature review, most prior studies find that center-based care is particularly beneficial for low-income children, many assume that child care subsidies should have positive developmental effects. As alluded to above, this assumption is not borne out by existing research (Herbst \& Tekin, 2010a; 2010b; 2012). Two results in this paper may lend some clarity to the negative CCDF results. First, I find that children using formal, centerbased care—where most subsidized children are placed — experience the largest reductions in mental ability test scores. Second, the group targeted by the CCDF-low-income children-does not perform better when they participate in non-parental care.

Once a clearer understanding of these complex child care effects is obtained, program administrators will be in a better position to make optimal funding and program design decisions. For example, if some non-parental arrangements are found to be particularly beneficial for some groups of children, while others are neutral or detrimental, such information can be used to direct quality enhancement funds more efficiently or place targeted quality requirements on providers using public funds. Such findings may also assist with parental decision-making regarding child care arrangements. Assuming that parents care about child care quality and child well-being, increasing access to information about the developmental effects of specific arrangements at specific ages can improve decision-making by allowing parents to purchase the type of care best suited to meet the needs of the child. 


\section{References}

Almond, D. \& Currie, J. (2010). Human capital development before age five. NBER Working Paper No. 15827. Cambridge, MA: National Bureau of Economic Research.

Angrist, J. \& Krueger, A. (1991). Does compulsory school attendance affect schooling and earnings? Quarterly Journal of Economics, 106, 979-1014.

Auinger, P., B.P. Lanphear, H.J. Kalkwarf, \& M.E. Mansour. (2003). Trends in otitis media among children in the United States. Pediatrics, 112, 514-520.

Becker, G. (1965). A theory of the allocation of time. Economic Journal, 40, 493-508.

Belsky, J \& Steinberg, L. (1978). The effects of day-care: A critical review. Child Development, 49, 929-949.

Belsky, J., Vandell, D. L., Burchinal, M., Clarke-Stewart, K. A., McCartney, K., Owen, M. T., et al. (2007). Are there long-term effects of early child care? Child Development, 78, 681-701.

Bernal, R. \& Keane, M. (2011). Child care choices and children's cognitive achievement: The case of single mothers. Journal of Labor Economics, 29, 459-512.

Blau, D. (1999). The effects of child care characteristics on child development. Journal of Human Resources, 34, 786-822.

Bound, J., Jaeger, D., \& Baker, R. (1995). Problems with instrumental variables estimation when the correlation between the instruments and the endogenous explanatory variable is weak. Journal of the American Statistical Association, 90, 443-450.

Bradley, R. \& Vandell D.L. (2007). Child care and the well-being of children. Arch Pediatr Adolesc Med, 161, 669-676.

Brooks-Gunn, J., Han, W.-J., \& Waldfogel, J. (2002). Maternal Employment and Child Cognitive Outcomes in the First Three Years of Life: The NICHD Study of Early Child Care. Child Development, 73, 1052-1072.

Buckles, K. \& Hungerman, D. (2010). Season of birth and later outcomes: Old questions, new answers. NBER Working Paper No. 14573. Cambridge, MA: National Bureau of Economic Research.

Camilli, G., Vargas, S., Ryan, S., \& Barnett, W.S. (2010). Metaanalysis of the effects of early education interventions on cognitive and social development. Teachers College Record, 112, Article 15440.

Cascio, E. \& Lewis, E. (2006). Schooling and the Armed Forces Qualifying Test. The Journal of Human Resources, XLI, 294-318.

Case, A., D. Lubotsky, \& C. Paxson. (2002). Economic Status and Health in Childhood: The Origins of the Gradient. American Economic Review, 92, 1308-34. 
Case, A., Fertig, A., \& Paxson, C. (2005). The lasting impact of childhood health and circumstance. Journal of Health Economics, 24, 365-389.

Currie, J. \& Hotz, V. J. (2004). Accidents will happen? Unintentional childhood injuries and the effects of child care regulations. Journal of Health Economics, 23, 25-59.

Deming, D. (2009). Early childhood intervention and life-cycle skill development: Evidence from Head Start. American Economic Journal: Applied Economics, 1, 111-134.

Gelbach, J. (2002). Public Schooling for Young Children and Maternal Labor Supply. American Economic Review, 92, 307-322.

Gershoff, E. (2002). Corporal punishment by parents and associated child behaviors and experiences: A meta-analytic and theoretical review. Psychological Bulletin, 128, 530-579.

Gordon, R., Kaestner, R., \& Korenman, S. (2007). The effects of maternal employment on child injuries and infectious disease. Demography, 44, 307-333.

Gormley, W., \& Gayer, T. (2005). Promoting school readiness in Oklahoma: An evaluation of Tulsa’s pre-k program. Journal of Human Resources, 40, 533-558.

Hansen, C., Hausman, J. \& Newey, W. (2008). Estimation with many instrumental variables. Journal of Business and Economic Statistics, 26, 398-422.

Herbst, C.M. \& Tekin, E. (2010a). The impact of child care subsidies on child well-being: Evidence from geographic variation in the distance to social service agencies. NBER Working Paper No. 16250.

Herbst, C., \& Tekin, E. (2010b). Child care subsidies and child development. Economics of Education Review, 29, 618-638.

Herbst, C.M. \& Tekin, E. (2012). The geographic accessibility of child care subsidies and evidence on the impact of subsidy receipt on childhood obesity. Journal of Urban Economics, 1, 3752.

Hill, J., Waldfogel, J., \& Brooks-Gunn, J. (2002). Differential effects of high quality child care. Journal of Policy Analysis and Management, 21, 601-627.

Hustedt, J.T., Barnett, W.S., Jung, K., \& Figueras, A. (2008). Impacts of New Mexico PreK on children's school readiness at kindergarten entry: Results from the second year of a growing initiative. New Brunswick: Rutgers, The State University of New Jersey, National Institute for Early Education Research.

Hustedt, J.T., Barnett, W.S., Jung, K., \& Thomas, J. (2007). The effects of the Arkansas Better Chance Program on young children's school readiness. New Brunswick: Rutgers, The State University of New Jersey, National Institute for Early Education Research. 
Ispa, J. M., Fine, M., Halgunseth, L. C., Harper, S., Robinson, J., Boyce, L. (2004). Maternal intrusiveness, maternal warmth, and mother-toddler relationship outcomes: Variations across lowincome ethnic and language groups. Child Development, 75, 1613-1631.

Karoly, L., Kilburn, R., \& Cannon, J. (2005). Early childhood interventions: Proven results, future promise. Santa Monica, CA: RAND Corporation.

Lam, D. \& Miron, J.A. (1991). Seasonality of births in human populations. Social Biology, 38,51-78.

Laughlin, L. (2010). Who’s minding the kids? Child care Arrangements: Spring 2005/Summer 2006. Current Population Reports P70-121. Washington, DC: U.S. Census Bureau.

Leibowitz, A. (1974). Home Investments in Children. Journal of Political Economy. 82(2):S111S131.

Loeb, S., Fuller, B., Kagan, S. \& Carrol, B. (2004). Child care in poor communities: Early learning effects of type, quality and stability. Child Development, 75, 47-65.

Ludwig, J. \& Miller, D. (2007). Does Head Start improve children’s life chances? Evidence from a regression discontinuity design. Quarterly Journal of Economics, 122, 159-208.

Morrill, M. (2011). The effects of maternal employment on the health of school-age children. Journal of Health Economics, 30, 240-257.

NICHD ECCRN. (1997a). Child care in the first year of life. Merrill-Palmer Quarterly, 43, 340-360.

NICHD ECCRN. (1997b). The effects of infant child care on infant-mother attachment security. Child Development, 68, 860-879.

NICHD ECCRN. (1998). Early child care and self-control, compliance, and problem behavior at twenty-four and thirty-six months. Child Development, 69, 1145-1170.

NICHD ECCRN. (1999). Child care and mother-child interaction in the first 3 years of life.

Developmental Psychology, 35, 1399-1413.

NICHD ECCRN. (2000a). Characteristics and quality of child care for toddlers and preschoolers. Applied Developmental Science, 4, 116-135.

NICHD ECCRN. (2000b). The relation of child care to cognitive and language development. Child Development, 71, 960-980.

NICHD ECCRN (2001a). Child care and family predictors of preschool attachment and stability from infancy. Developmental Psychology, 37, 847-862.

NICHD ECCRN. (2001b). Child Care and Common Communicable Illnesses. Archives of Pediatric Adolescent Medicine, 155, 481-488.

NICHD ECCRN. (2001c). Child care and children's peer interaction at 24 and 36 months: The NICHD study of early child care. Child Development, 72, 1478-1500. 
NICHD ECCRN. (2003a). Child Care and Common Communicable Illnesses in Children Aged 37 to 54 Months. Archives of Pediatric Adolescent Medicine, 157, 196-200.

NICHD ECCRN. (2003b). Does amount of time spent in child care predict socioemotional adjustment during the transition to kindergarten? Child Development, 74, 976-1005.

NICHD ECCRN. (2004). Type of child care and children's development at 54-months. Early Childhood Research Quarterly, 19, 203-230.

NICHD ECCRN \& Duncan, G. (2003). Modeling the impacts of child care quality on children's preschool cognitive development. Child Development, 74, 1454-1475.

Pianta, R., W. Steven Barnett, Margaret Burchinal, \& Kathy R. Thornburg. (2009). The Effects of preschool education: What we know, how public policy is or is not aligned with the evidence base, and what we need to know. Psychological Science in the Public Interest, 10, 49-88.

Peisner-Feinberg, E., Burchinal, M., Clifford, R., Culkin, M., Howes, C., Kagan, S., \& Yazejian, N. (2001). The relation of preschool child-care quality to children's cognitive and social development trajectories through second grade. Child Development, 72, 1534-1553.

Raver, C. (2002). Emotions matter: Making the case for the role of young children's emotional development for early school readiness. Social Policy Report of the Society for Research in Child Development, 16, 1-20.

Ruhm, C. (2004). Parental employment and child cognitive development. Journal of Human Resources, 39, 155-192.

U.S. Department of Health and Human Services, Administration for Children and Families. (2005). Head start impact study: First year findings. Washington, DC: U.S. Department of Health and Human Services.

U.S. Department of Health and Human Services, Administration for Children and Families. (2010). Head start impact study: Final report. Washington, DC: U.S. Department of Health and Human Services.

Todd, P. \& Wolpin, K. (2003). On the specification and estimation of the production function for cognitive achievement. The Economic Journal, 113, F3-F33.

Todd, P. \& Wolpin, K. (2007). The production of cognitive achievement in children: Home, school, and racial test score gaps. Journal of Human Capital, 1, 91-136.

Wong, V.C., Cook, T.D., Barnett, W.S., \& Jung, K. (2008). An effectiveness-based evaluation of five state pre-kindergarten programs. Journal of Policy Analysis and Management, 27, $122-154$. 


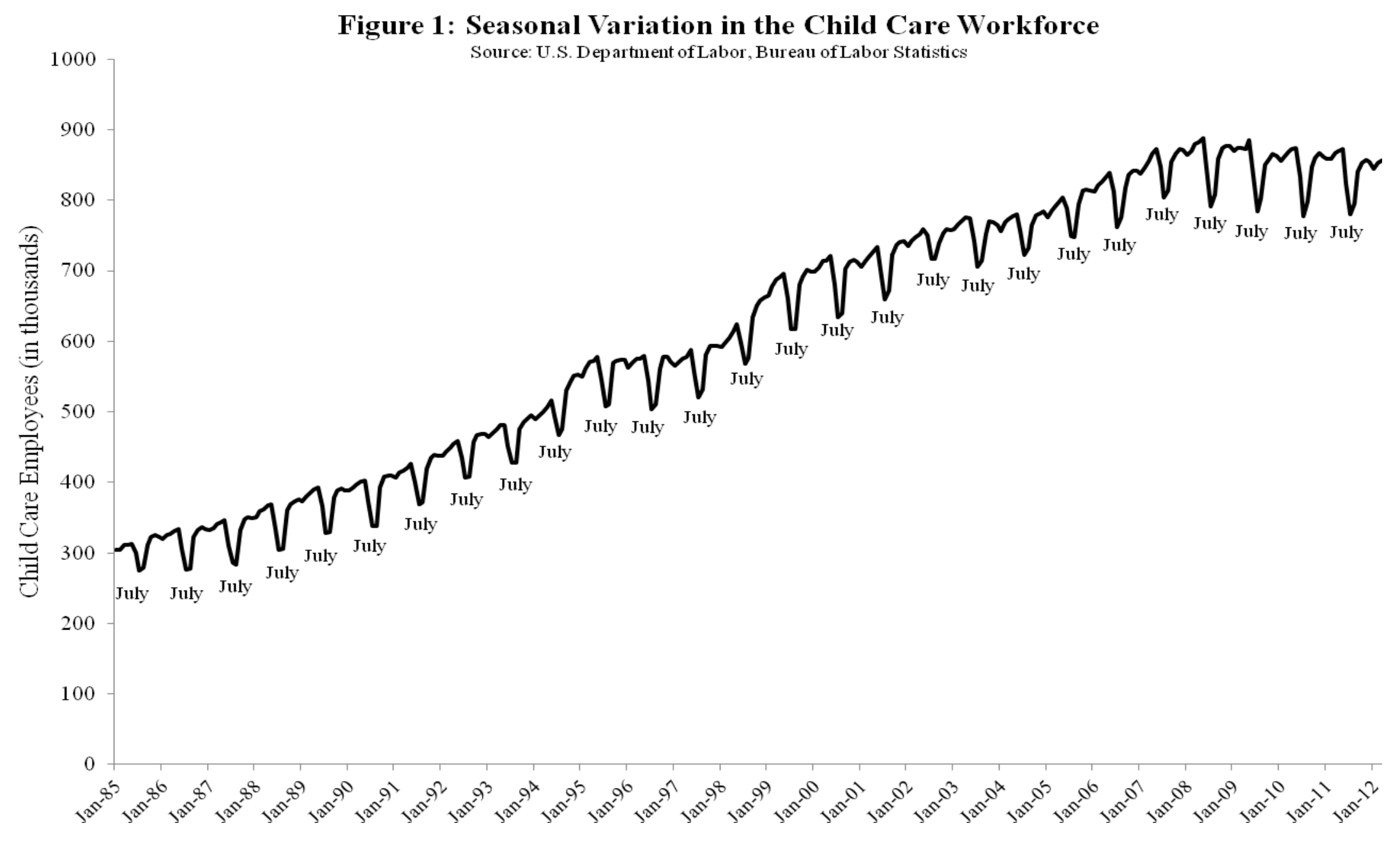



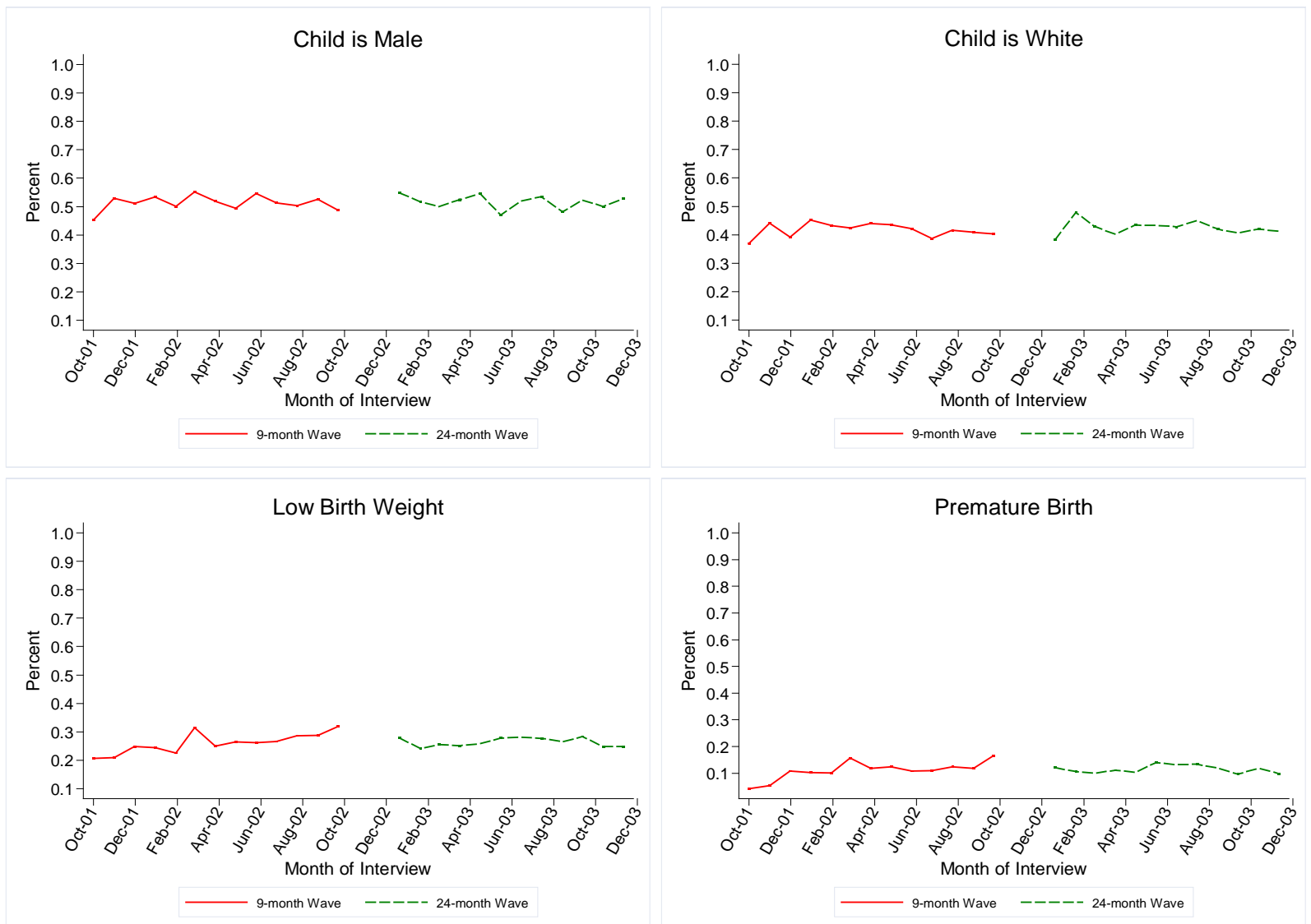

Figure 2: Child Characteristics by Month of ECLS-B Assessment 

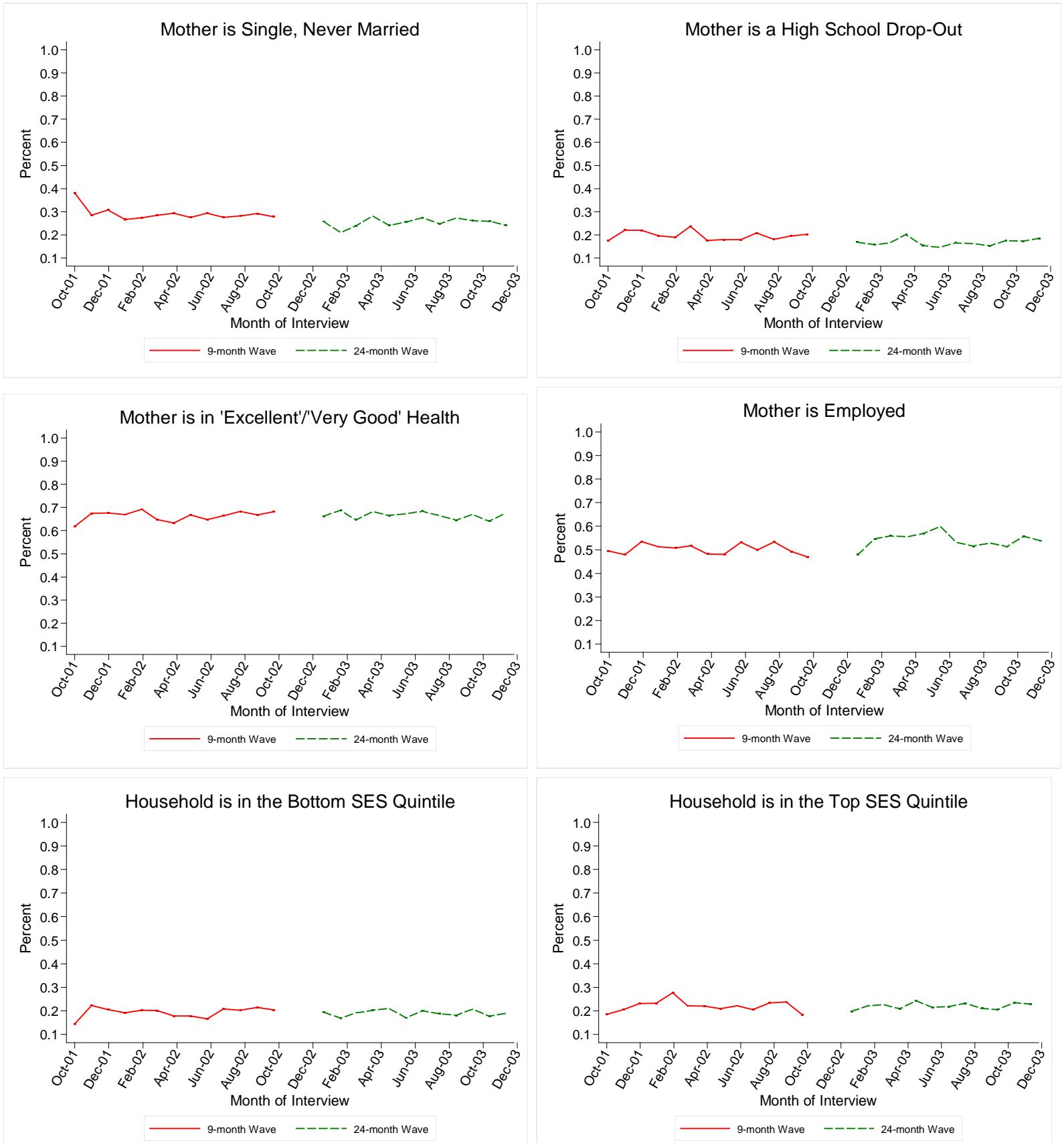

Figure 3: Family Characteristics by Month of ECLS-B Assessment 
Table 1: Summary Statistics

\begin{tabular}{|c|c|c|c|}
\hline Variable & $\begin{array}{c}\text { Full } \\
\text { Sample }\end{array}$ & $\begin{array}{l}\text { Non-Parental } \\
\text { Child Care }\end{array}$ & $\begin{array}{c}\text { Parental } \\
\text { Child Care }\end{array}$ \\
\hline \multicolumn{4}{|l|}{ Outcome } \\
\hline Bailey Short Form mental test score (9-months) & $\begin{array}{c}74.84 \\
(10.08)\end{array}$ & $\begin{array}{c}75.34 \\
(10.05)\end{array}$ & $\begin{array}{c}74.34 \\
(10.07)\end{array}$ \\
\hline Bailey Short Form mental test score (24-months) & $\begin{array}{l}125.53 \\
(10.99)\end{array}$ & $\begin{array}{l}126.40 \\
(11.05)\end{array}$ & $\begin{array}{l}124.67 \\
(10.87)\end{array}$ \\
\hline \multicolumn{4}{|l|}{ Child Characteristics } \\
\hline Male (\%) & $\begin{array}{c}0.511 \\
(0.500)\end{array}$ & $\begin{array}{c}0.512 \\
(0.500)\end{array}$ & $\begin{array}{c}0.510 \\
(0.500)\end{array}$ \\
\hline Age (months) & $\begin{array}{l}17.14 \\
(7.14)\end{array}$ & $\begin{array}{l}17.15 \\
(7.13)\end{array}$ & $\begin{array}{l}17.12 \\
(7.14)\end{array}$ \\
\hline White (\%) & $\begin{array}{c}0.421 \\
(0.494)\end{array}$ & $\begin{array}{c}0.409 \\
(0.492)\end{array}$ & $\begin{array}{c}0.432 \\
(0.495)\end{array}$ \\
\hline Low birth weight (\%) & $\begin{array}{c}0.263 \\
(0.440)\end{array}$ & $\begin{array}{c}0.262 \\
(0.440)\end{array}$ & $\begin{array}{c}0.264 \\
(0.441)\end{array}$ \\
\hline Premature birth (\%) & $\begin{array}{c}0.115 \\
(0.319)\end{array}$ & $\begin{array}{c}0.114 \\
(0.318)\end{array}$ & $\begin{array}{c}0.116 \\
(0.320)\end{array}$ \\
\hline Weight (kilograms) & $\begin{array}{l}10.85 \\
(2.44)\end{array}$ & $\begin{array}{l}10.92 \\
(2.42)\end{array}$ & $\begin{array}{l}10.77 \\
(2.45)\end{array}$ \\
\hline Family Characteristics & & & \\
\hline Mother's age (years) & $\begin{array}{l}29.17 \\
(6.67)\end{array}$ & $\begin{array}{l}29.11 \\
(6.71)\end{array}$ & $\begin{array}{l}29.23 \\
(6.63)\end{array}$ \\
\hline Mother is single, never married (\%) & $\begin{array}{c}0.266 \\
(0.442)\end{array}$ & $\begin{array}{c}0.294 \\
(0.456)\end{array}$ & $\begin{array}{c}0.238 \\
(0.426)\end{array}$ \\
\hline Mother is married (\%) & $\begin{array}{c}0.668 \\
(0.471)\end{array}$ & $\begin{array}{c}0.626 \\
(0.484)\end{array}$ & $\begin{array}{c}0.708 \\
(0.455)\end{array}$ \\
\hline Mother is a high school drop-out (\%) & $\begin{array}{c}0.179 \\
(0.383)\end{array}$ & $\begin{array}{c}0.129 \\
(0.336)\end{array}$ & $\begin{array}{c}0.227 \\
(0.419)\end{array}$ \\
\hline Mother has a BA+ (\%) & $\begin{array}{c}0.269 \\
(0.443)\end{array}$ & $\begin{array}{c}0.300 \\
(0.458)\end{array}$ & $\begin{array}{c}0.238 \\
(0.426)\end{array}$ \\
\hline Mother is employed (\%) & $\begin{array}{c}0.523 \\
(0.500)\end{array}$ & $\begin{array}{c}0.818 \\
(0.386)\end{array}$ & $\begin{array}{c}0.233 \\
(0.423)\end{array}$ \\
\hline Household income $(\$ / 1,000)$ & $\begin{array}{c}51.558 \\
(45.402)\end{array}$ & $\begin{array}{c}57.317 \\
(48.518)\end{array}$ & $\begin{array}{c}45.871 \\
(41.321)\end{array}$ \\
\hline Focal child is an only-child (\%) & $\begin{array}{c}0.335 \\
(0.472)\end{array}$ & $\begin{array}{c}0.382 \\
(0.486)\end{array}$ & $\begin{array}{c}0.287 \\
(0.453)\end{array}$ \\
\hline Urban residence (\%) & $\begin{array}{c}0.847 \\
(0.361)\end{array}$ & $\begin{array}{c}0.842 \\
(0.364)\end{array}$ & $\begin{array}{c}0.851 \\
(0.357)\end{array}$ \\
\hline
\end{tabular}

Source: Author's analysis of the 9- and 24-month waves of the ECLS-B.

Notes: Standard deviations are displayed in parentheses. The means come from the pooled 9- and 24-month sample. 
Table 2: Child Care Participation Profile at 9- and 24-Months

\begin{tabular}{lccc}
\hline Variable & $\begin{array}{c}\text { Pooled } \\
\text { Periods }\end{array}$ & $\begin{array}{c}\text { 9-Month } \\
\text { Survey }\end{array}$ & $\begin{array}{c}\text { 24-Month } \\
\text { Survey }\end{array}$ \\
\hline Panel A: Primary Measure & & & \\
Non-parental child care (\%) & 0.497 & 0.499 & 0.494 \\
& $(0.500)$ & $(0.500)$ & $(0.500)$ \\
\multicolumn{1}{c}{ Average weekly hours (no.) } & 32.68 & 32.15 & 33.28 \\
& $(17.26)$ & $(18.26)$ & $(16.06)$ \\
Panel B: Alternative Measure & & & \\
Informal child care (\%) & 0.270 & 0.301 & 0.227 \\
\multicolumn{1}{c}{ Average weekly hours (no.) } & $(0.444)$ & $(0.462)$ & $(0.419)$ \\
& 28.49 & 27.41 & 30.12 \\
& $(16.72)$ & $(16.96)$ & $(16.23)$ \\
Formal child care (\%) & 0.224 & 0.186 & 0.265 \\
\multicolumn{1}{c}{ Average weekly hours (no.) } & $(0.417)$ & $(0.389)$ & $(0.441)$ \\
& 32.20 & 32.12 & 32.26 \\
& $(13.61)$ & $(13.91)$ & $(13.39)$ \\
Panel C: Alternative Measure & & & \\
Cumulative Child Care (no. months) & 6.76 & 3.66 & 10.92 \\
& $(8.09)$ & $(3.96)$ & $(10.09)$ \\
\hline
\end{tabular}

Source: Author's analysis of the 9- and 24-month waves of the ECLS-B.

Notes: Standard deviations are displayed in parentheses. Informal care includes relative care in any home and non-relative care in the child's home. Formal care includes non-relative care in another's home and center-based care. The figures for average weekly hours in Panel A represent the sum of hours in non-parental child care over all arrangements. The analogous figures in Panel B represent the number of hours in informal or formal care for the arrangement in which the child spent the greatest number of hours. All hours of care calculations are based on the sub-set of children using nonparental child care. 
Table 3: ECLS-B Assessment Schedule Month and Year Number of

of Assessment

Assessments

Wave 1: 9-Month Survey

$\begin{array}{lc}\text { Oct-01 } & 97 \\ \text { Nov-01 } & 934 \\ \text { Dec-01 } & 685 \\ \text { Jan-02 } & 954 \\ \text { Feb-02 } & 911 \\ \text { Mar-02 } & 551 \\ \text { Apr-02 } & 900 \\ \text { May-02 } & 826 \\ \text { Jun-02 } & 816 \\ \text { July-02 } & 865 \\ \text { Aug-02 } & 935 \\ \text { Sep-02 } & 813 \\ \text { Oct-02 } & 538 \\ \text { Nov-02 } & 289 \\ \text { Dec-02 } & 66\end{array}$

Wave 2: 24-Month Survey

\begin{tabular}{lc} 
Jan-03 & 237 \\
Feb-03 & 994 \\
Mar-03 & 1,047 \\
Apr-03 & 925 \\
May-03 & 837 \\
Jun-03 & 740 \\
Jul-03 & 822 \\
Aug-03 & 831 \\
Sep-03 & 795 \\
Oct-03 & 822 \\
Nov-03 & 704 \\
Dec-03 & 466 \\
Apr-04 & 16 \\
\hline ource: Author's analysis of the 9- and 24-month waves of \\
ECLS-B
\end{tabular}


Table 4: First-Stage Estimates of the Relationship between ECLS-B Assessment Timing and Current Non-Parental Child Care Utilization

\begin{tabular}{|c|c|c|c|c|c|}
\hline \multirow[b]{2}{*}{ Variable } & \multicolumn{3}{|c|}{ Non-Parental Care } & \multirow{2}{*}{$\begin{array}{c}\text { Informal Care } \\
(4)\end{array}$} & \multirow{2}{*}{$\begin{array}{c}\text { Formal Care } \\
\text { (5) }\end{array}$} \\
\hline & (1) & (2) & (3) & & \\
\hline \multirow[t]{2}{*}{ Summer assessment } & $-0.026 * * *$ & $-0.027 * * *$ & $-0.027 * * *$ & $-0.024 * * *$ & $-0.023 * * *$ \\
\hline & $(0.006)$ & $(0.006)$ & $(0.006)$ & $(0.007)$ & $(0.007)$ \\
\hline \multirow[t]{2}{*}{ F-statistic ( $p$-value) } & 17.53 & 19.63 & 18.74 & 12.57 & 11.62 \\
\hline & $(0.000)$ & $(0.000)$ & $(0.000)$ & $(0.000)$ & $(0.000)$ \\
\hline Child characteristics & $\mathrm{Y}$ & $\mathrm{Y}$ & $\mathrm{Y}$ & $\mathrm{Y}$ & $\mathrm{Y}$ \\
\hline Family characteristics & $\mathrm{Y}$ & $\mathrm{Y}$ & $\mathrm{Y}$ & $\mathrm{Y}$ & $\mathrm{Y}$ \\
\hline Family characteristics $\times$ wave & $\mathrm{Y}$ & $\mathrm{Y}$ & $\mathrm{Y}$ & $\mathrm{Y}$ & $\mathrm{Y}$ \\
\hline State fixed effects with wave interactions & $\mathrm{N}$ & $\mathrm{Y}$ & $\mathrm{Y}$ & $\mathrm{Y}$ & $\mathrm{Y}$ \\
\hline Quarter-of-birth & $\mathrm{N}$ & $\mathrm{N}$ & $\mathrm{Y}$ & $\mathrm{N}$ & $\mathrm{N}$ \\
\hline Number of observations & 19,416 & 19,416 & 19,416 & 14,976 & 14,079 \\
\hline
\end{tabular}

Source: Author's analysis of the 9- and 24-month waves of the ECLS-B.

Notes: Standard errors are displayed in parentheses and are adjusted for within-child clustering. The summer assessment variable is a binary indicator for whether a given child was assessed (and parents were interviewed) in the summer (i.e., June, July, August, or September) during the 9- or 24-month survey. The dependent

variable in columns (1) through (3) is a binary indicator for participation in any non-parental child care arrangement. The dependent variable in column (4) is a binary indicator for participation in an informal arrangement (and equals zero for participation in parent care). The dependent variable in column (5) is a binary indicator for participation in a formal arrangement (and equals zero for participation in parent care). The child characteristics include gender, age (up to a quartic polynomial), race and ethnicity (four dummy variables), low birth weight (one dummy variable), premature birth (one dummy variable), and weight (in kilograms). The family controls include mother's age (up to a squared polynomial), marital status (four dummy variables), mother's education (three dummy variables), the presence of other siblings in the household (three dummy variables), mother's employment status (three dummy variables), total household income (12 dummy variables), and urban residence (one dummy variable). All models include a binary indicator for wave. ***, **, * indicate statistical significance at the $0.01,0.05$, and 0.10 levels, respectively. 
Table 5: Child Characteristics by Month of ECLS-B Assessment

\begin{tabular}{|c|c|c|c|c|c|}
\hline Month of Assessment & $\begin{array}{c}\text { Male } \\
\text { (1) }\end{array}$ & $\begin{array}{c}\text { White } \\
(2)\end{array}$ & $\begin{array}{c}\text { LBW } \\
\text { (3) }\end{array}$ & $\begin{array}{c}\text { Premature } \\
\text { (4) }\end{array}$ & $\begin{array}{c}\text { Weight } \\
\text { (5) }\end{array}$ \\
\hline \multicolumn{6}{|l|}{ Panel A: No Controls } \\
\hline June & $\begin{array}{l}-0.007 \\
(0.014)\end{array}$ & $\begin{array}{c}0.000 \\
(0.014)\end{array}$ & $\begin{array}{c}0.014 \\
(0.012)\end{array}$ & $\begin{array}{c}0.012 \\
(0.009)\end{array}$ & $\begin{array}{l}-0.036 \\
(0.048)\end{array}$ \\
\hline July & $\begin{array}{l}-0.000 \\
(0.013)\end{array}$ & $\begin{array}{c}-0.019 \\
(0.013)\end{array}$ & $\begin{array}{c}0.017 \\
(0.012)\end{array}$ & $\begin{array}{c}0.009 \\
(0.009)\end{array}$ & $\begin{array}{l}-0.035 \\
(0.049)\end{array}$ \\
\hline August & $\begin{array}{c}0.002 \\
(0.013)\end{array}$ & $\begin{array}{c}0.007 \\
(0.013)\end{array}$ & $\begin{array}{l}0.026^{* *} \\
(0.012)\end{array}$ & $\begin{array}{c}0.017^{*} \\
(0.009)\end{array}$ & $\begin{array}{l}-0.050 \\
(0.048)\end{array}$ \\
\hline September & $\begin{array}{l}-0.011 \\
(0.014)\end{array}$ & $\begin{array}{l}-0.011 \\
(0.013)\end{array}$ & $\begin{array}{c}0.020 \\
(0.012)\end{array}$ & $\begin{array}{c}0.008 \\
(0.009)\end{array}$ & $\begin{array}{c}0.036 \\
(0.051)\end{array}$ \\
\hline F-statistic ( $p$-value) & $\begin{array}{c}0.24 \\
(0.918)\end{array}$ & $\begin{array}{c}0.80 \\
(0.527)\end{array}$ & $\begin{array}{c}1.88 \\
(0.111)\end{array}$ & $\begin{array}{c}1.26 \\
(0.285)\end{array}$ & $\begin{array}{c}0.67 \\
(0.615)\end{array}$ \\
\hline \multicolumn{6}{|l|}{ Panel B: Includes Controls } \\
\hline June & $\begin{array}{l}-0.003 \\
(0.014)\end{array}$ & $\begin{array}{c}-0.002 \\
(0.011)\end{array}$ & $\begin{array}{l}-0.002 \\
(0.010)\end{array}$ & $\begin{array}{c}0.006 \\
(0.007)\end{array}$ & $\begin{array}{l}-0.053 \\
(0.044)\end{array}$ \\
\hline July & $\begin{array}{c}0.002 \\
(0.013)\end{array}$ & $\begin{array}{l}-0.017 \\
(0.011)\end{array}$ & $\begin{array}{c}0.006 \\
(0.010)\end{array}$ & $\begin{array}{c}0.002 \\
(0.007)\end{array}$ & $\begin{array}{l}-0.065 \\
(0.044)\end{array}$ \\
\hline August & $\begin{array}{c}0.004 \\
(0.013)\end{array}$ & $\begin{array}{l}-0.003 \\
(0.011)\end{array}$ & $\begin{array}{c}0.012 \\
(0.009)\end{array}$ & $\begin{array}{c}0.011 \\
(0.007)\end{array}$ & $\begin{array}{l}-0.025 \\
(0.043)\end{array}$ \\
\hline September & $\begin{array}{l}-0.012 \\
(0.014)\end{array}$ & $\begin{array}{l}-0.007 \\
(0.012)\end{array}$ & $\begin{array}{c}0.012 \\
(0.010)\end{array}$ & $\begin{array}{l}-0.002 \\
(0.007)\end{array}$ & $\begin{array}{l}-0.004 \\
(0.046)\end{array}$ \\
\hline F-statistic ( $p$-value) & $\begin{array}{c}0.28 \\
(0.894)\end{array}$ & $\begin{array}{c}0.60 \\
(0.662)\end{array}$ & $\begin{array}{c}0.84 \\
(0.502)\end{array}$ & $\begin{array}{c}0.72 \\
(0.581)\end{array}$ & $\begin{array}{c}0.84 \\
(0.501)\end{array}$ \\
\hline Number of observations & 19,416 & 19,379 & 19,339 & 19,032 & 18,590 \\
\hline
\end{tabular}


Table 7: Comparison of Non-Parental Child Care Environments across the Summer and Non-Summer Months, 24-Month Wave

\begin{tabular}{|c|c|c|c|c|}
\hline \multirow[b]{2}{*}{ Dependent Variable } & \multirow[b]{2}{*}{$\mathbf{N}$} & \multirow[b]{2}{*}{ Mean } & \multicolumn{2}{|c|}{$\begin{array}{c}\text { Coefficient on } \\
\text { Summer Assessment }\end{array}$} \\
\hline & & & (1) & (2) \\
\hline \multicolumn{5}{|l|}{ Panel A: Global Child Care Quality } \\
\hline ITERS for center-based settings (range: 1-7) & 596 & 4.163 & $\begin{array}{c}0.003 \\
(0.086)\end{array}$ & $\begin{array}{l}-0.110 \\
(0.086)\end{array}$ \\
\hline FDCRS for home-based settings (range: 1-7) & 776 & 3.403 & $\begin{array}{c}0.004 \\
(0.079)\end{array}$ & $\begin{array}{l}-0.011 \\
(0.070)\end{array}$ \\
\hline Arnett Scale of Caregiver Behavior & 1,359 & 60.85 & $\begin{array}{l}-0.086 \\
(0.613)\end{array}$ & $\begin{array}{l}-0.237 \\
(0.591)\end{array}$ \\
\hline \multicolumn{5}{|c|}{ Panel B: Characteristics of the Child Care Center Director } \\
\hline B.A. degree or more (\%) & 568 & 0.528 & $\begin{array}{l}-0.025 \\
(0.044)\end{array}$ & $\begin{array}{c}0.006 \\
(0.045)\end{array}$ \\
\hline Child Development Associate credential (\%) & 561 & 0.301 & $\begin{array}{l}-0.031 \\
(0.040)\end{array}$ & $\begin{array}{l}-0.043 \\
(0.044)\end{array}$ \\
\hline Degree in early childhood education (\%) & 568 & 0.489 & $\begin{array}{l}-0.010 \\
(0.044)\end{array}$ & $\begin{array}{l}-0.015 \\
(0.045)\end{array}$ \\
\hline Experience in child care/education (years) & 570 & 14.79 & $\begin{array}{l}-2.104^{* * *} \\
(0.708)\end{array}$ & $\begin{array}{l}-1.570^{*} \\
(0.818)\end{array}$ \\
\hline \multicolumn{5}{|l|}{ Panel C: Characteristics of the Caregiver } \\
\hline Female (\%) & 3,066 & 0.967 & $\begin{array}{l}-0.001 \\
(0.007)\end{array}$ & $\begin{array}{c}0.002 \\
(0.007)\end{array}$ \\
\hline Born in the U.S. (\%) & 3,058 & 0.810 & $\begin{array}{c}0.004 \\
(0.015)\end{array}$ & $\begin{array}{l}-0.005 \\
(0.013)\end{array}$ \\
\hline Black (\%) & 3,032 & 0.211 & $\begin{array}{r}0.030^{*} \\
(0.016)\end{array}$ & $\begin{array}{l}-0.010 \\
(0.011)\end{array}$ \\
\hline High school degree or more (\%) & 3,057 & 0.826 & $\begin{array}{l}-0.010 \\
(0.015)\end{array}$ & $\begin{array}{l}-0.010 \\
(0.015)\end{array}$ \\
\hline Child Development Associate credential (\%) & 2,517 & 0.167 & $\begin{array}{l}0.045^{* * *} \\
(0.016)\end{array}$ & $\begin{array}{r}0.029 * \\
(0.016)\end{array}$ \\
\hline Experience in child care field (years) & 3,052 & 9.742 & $\begin{array}{l}-0.261 \\
(0.361)\end{array}$ & $\begin{array}{l}-0.256 \\
(0.367)\end{array}$ \\
\hline Reported health is excellent/very good (\%) & 3,058 & 0.712 & $\begin{array}{c}0.004 \\
(0.018)\end{array}$ & $\begin{array}{c}0.008 \\
(0.018)\end{array}$ \\
\hline Smokes cigarettes (\%) & 3,059 & 0.133 & $\begin{array}{l}-0.004 \\
(0.013)\end{array}$ & $\begin{array}{l}-0.013 \\
(0.013)\end{array}$ \\
\hline Time difference: child/provider assessment & & & $\mathrm{Y}$ & Y \\
\hline Child characteristics & & & $\mathrm{N}$ & $\mathrm{Y}$ \\
\hline Family characteristics & & & $\mathrm{N}$ & $\mathrm{Y}$ \\
\hline State fixed effects & & & $\mathrm{N}$ & $\mathrm{Y}$ \\
\hline
\end{tabular}


Table 8: The Relationship between Assessment and Birth Timing in the ECLS-B

\begin{tabular}{lcccc}
\hline & \multicolumn{3}{c}{ Quarter-of-Birth (2001, \%) } \\
Month-of-Assessment & QOB-1 & QOB-2 & QOB-3 & QOB-4 \\
\hline Panel A: 9-Month Survey (2002) & & & & \\
June & 0.048 & 0.214 & 0.708 & 0.029 \\
& $(0.213)$ & $(0.411)$ & $(0.455)$ & $(0.169)$ \\
July & 0.042 & 0.123 & 0.468 & 0.368 \\
& $(0.200)$ & $(0.328)$ & $(0.499)$ & $(0.482)$ \\
August & 0.026 & 0.062 & 0.244 & 0.669 \\
& $(0.158)$ & $(0.241)$ & $(0.430)$ & $(0.471)$ \\
September & 0.028 & 0.058 & 0.191 & 0.723 \\
& $(0.166)$ & $(0.234)$ & $(0.393)$ & $(0.448)$ \\
Panel B: 24-Month Survey (2003) & & & & \\
June & 0.107 & 0.815 & 0.078 & 0.000 \\
& $(0.309)$ & $(0.387)$ & $(0.269)$ & $(0.000)$ \\
July & 0.024 & 0.313 & 0.663 & 0.000 \\
& $(0.154)$ & $(0.464)$ & $(0.473)$ & $(0.000)$ \\
August & 0.018 & 0.108 & 0.865 & 0.008 \\
& $(0.133)$ & $(0.311)$ & $(0.342)$ & $(0.091)$ \\
September & 0.016 & 0.058 & 0.689 & 0.237 \\
& $(0.127)$ & $(0.234)$ & $(0.463)$ & $(0.425)$ \\
\hline
\end{tabular}

Source: Author's analysis of the 9- and 24-month waves of the ECLS-B.

Notes: Standard deviations are displayed in parentheses. Each cell depicts the fraction of children born in each calendar quarter (quarter-of-birth) by the summer month in which children are assessed (month-of-interview) during the 9- and 24-month surveys. Each row sums to one (100 percent). 
Table 9: OLS and Fixed Effects Estimates of the Impact of Current Non-Parental Child Care Utilization

\begin{tabular}{|c|c|c|c|c|c|c|}
\hline Variable & $\begin{array}{l}\text { OLS } \\
(1)\end{array}$ & $\begin{array}{l}\text { OLS } \\
(2)\end{array}$ & $\begin{array}{c}\text { OLS } \\
\text { (3) }\end{array}$ & $\begin{array}{c}\text { OLS } \\
\text { (4) }\end{array}$ & $\begin{array}{c}\text { Child FE } \\
\text { (5) }\end{array}$ & $\begin{array}{c}\text { Child FE } \\
\text { (6) }\end{array}$ \\
\hline Non-parental child care & $\begin{array}{l}0.014 * * * \\
(0.002)\end{array}$ & $\begin{array}{l}0.010^{* * *} \\
(0.001)\end{array}$ & $\begin{array}{c}0.003 * \\
(0.002)\end{array}$ & $\begin{array}{c}0.003^{*} \\
(0.002)\end{array}$ & $\begin{array}{l}0.008 * * * \\
(0.003)\end{array}$ & $\begin{array}{c}0.004^{*} \\
(0.002)\end{array}$ \\
\hline
\end{tabular}

\begin{tabular}{|c|c|c|c|c|c|c|}
\hline Child characteristics & $\mathrm{N}$ & $\mathrm{Y}$ & $\mathrm{Y}$ & $\mathrm{Y}$ & $\mathrm{N}$ & $\mathrm{Y}$ \\
\hline Family characteristics & $\mathrm{N}$ & $\mathrm{N}$ & $\mathrm{Y}$ & $\mathrm{Y}$ & $\mathrm{N}$ & $\mathrm{Y}$ \\
\hline Family characteristics $\times$ wave & $\mathrm{N}$ & $\mathrm{N}$ & $\mathrm{Y}$ & $\mathrm{Y}$ & $\mathrm{N}$ & $\mathrm{Y}$ \\
\hline State fixed effects with wave interactions & $\mathrm{N}$ & $\mathrm{N}$ & $\mathrm{N}$ & $\mathrm{Y}$ & $\mathrm{N}$ & $\mathrm{N}$ \\
\hline
\end{tabular}

State fixed effects with wave interactions

Notes: Standard errors are displayed in parentheses and are adjusted for within-child clustering. The outcome in all models is the natural log of the Bailey Short Form-

Research Edition mental test score. The omitted category in Panel B is parental child care. Informal care includes relative care in any home and non-relative care in the child's

home. Formal care includes non-relative care in another's home and center-based care. See Table 4 for a list of the controls included in the models. All models include a binary indicator for wave. All analyses are based on 10,201 children, providing 19,071 child-wave combinations. ***, **, * indicate statistical significance at the $0.01,0.05$, and 0.10 levels, respectively. 
Table 10: Instrumental Variables Estimates of the Impact of Current Non-Parental Child Care Utilization

\begin{tabular}{|c|c|c|c|c|c|c|}
\hline Variable & $\begin{array}{c}\text { First } \\
\text { Stage } \\
(1) \\
\end{array}$ & $\begin{array}{l}\text { Reduced } \\
\text { Form } \\
(2) \\
\end{array}$ & $\begin{array}{c}\text { IV } \\
\text { 2SLS } \\
(3) \\
\end{array}$ & $\begin{array}{c}\text { IV } \\
\text { 2SLS } \\
(4) \\
\end{array}$ & $\begin{array}{c}\text { IV } \\
\text { FE-1 } \\
\text { (5) }\end{array}$ & $\begin{array}{c}\text { IV } \\
\text { FE-2 } \\
\text { (6) }\end{array}$ \\
\hline Non-parental child care / & $-0.026 * * *$ & $0.003 * *$ & $-0.094 * *$ & $-0.085 * *$ & -0.105 & $-0.092 *$ \\
\hline Summer assessment & $(0.006)$ & $(0.001)$ & $(0.039)$ & $(0.039)$ & $(0.146)$ & $(0.054)$ \\
\hline Child characteristics & $\mathrm{Y}$ & $\mathrm{Y}$ & $\mathrm{Y}$ & $\mathrm{Y}$ & $\mathrm{Y}$ & $\mathrm{Y}$ \\
\hline Family characteristics & $\mathrm{Y}$ & $\mathrm{Y}$ & $\mathrm{Y}$ & $\mathrm{Y}$ & $\mathrm{Y}$ & $\mathrm{Y}$ \\
\hline Family characteristics $\times$ wave & $\mathrm{Y}$ & $\mathrm{Y}$ & $\mathrm{Y}$ & $\mathrm{Y}$ & $\mathrm{Y}$ & $\mathrm{Y}$ \\
\hline State fixed effects with wave interactions & $\mathrm{Y}$ & $\mathrm{Y}$ & $\mathrm{Y}$ & $\mathrm{Y}$ & $\mathrm{N}$ & $\mathrm{N}$ \\
\hline Quarter-of-birth & $\mathrm{N}$ & $\mathrm{N}$ & $\mathrm{N}$ & $Y$ & $\mathrm{~N}$ & $\mathrm{~N}$ \\
\hline
\end{tabular}

Source: Author's analysis of the 9- and 24-month waves of the ECLS-B.

Notes: Standard errors are displayed in parentheses and are adjusted for within-child clustering. The outcome column (1) is the binary indicator of non-parental child care utilization. The outcome in columns (2) through (6) is the log of the Bailey Short Form Research-Edition mental test score. The instrument in columns (3) through (5) is the binary indicator for a summer assessment. The instruments in column (6) include a set of binary indicators for each summer month (i.e., June through September) in each ECLS-B survey wave (i.e., 9- and 24-month), for a total of eight instruments. See Table 4 for a list of the controls included in the models. All models include a binary indicator for wave. All analyses are based on 10,201 children, providing 19,071 child-wave combinations. ***, **, * indicate statistical significance at the 0.01 , 0.05 , and 0.10 levels, respectively. 
Table 11: OLS, Fixed Effects, and Instrumental Variables Estimates of the Impact of Cumulative Non-Parental Child Care Utilization

\begin{tabular}{|c|c|c|c|c|c|c|}
\hline Variable & $\begin{array}{c}\text { First } \\
\text { Stage } \\
\text { (1) }\end{array}$ & $\begin{array}{c}\text { First } \\
\text { Stage } \\
\text { (2) }\end{array}$ & $\begin{array}{c}\text { OLS } \\
\text { Full } \\
(3)\end{array}$ & $\begin{array}{c}\text { Child } \\
\text { FE } \\
(4)\end{array}$ & $\begin{array}{c}\text { IV } \\
\text { 2SLS } \\
(5)\end{array}$ & $\begin{array}{c}\text { IV } \\
2 S L S \\
(6)\end{array}$ \\
\hline Summer assessment / & $-0.385 * * *$ & $-0.368 * * *$ & $0.0004^{* * *}$ & $0.001 * *$ & $-0.008 * *$ & $-0.007 * *$ \\
\hline Cumulative child care & $(0.096)$ & $(0.099)$ & $(0.0001)$ & $(0.0002)$ & $(0.003)$ & $(0.003)$ \\
\hline F-statistic ( $p$-value) & 16.23 & 13.73 & $\mathrm{~N} / \mathrm{A}$ & N/A & N/A & N/A \\
\hline Child characteristics & $\mathrm{Y}$ & $\mathrm{Y}$ & $\mathrm{Y}$ & $\mathrm{Y}$ & $\mathrm{Y}$ & $\mathrm{Y}$ \\
\hline Family characteristics & $\mathrm{Y}$ & $\mathrm{Y}$ & $\mathrm{Y}$ & $\mathrm{Y}$ & $\mathrm{Y}$ & $\mathrm{Y}$ \\
\hline State fixed effects with wave interactions & $\mathrm{Y}$ & $\mathrm{Y}$ & $\mathrm{Y}$ & $\mathrm{N}$ & $\mathrm{Y}$ & $\mathrm{Y}$ \\
\hline Quarter-of-birth & $\mathrm{N}$ & $\mathrm{Y}$ & $\mathrm{N}$ & $\mathrm{N}$ & $\mathrm{N}$ & $\mathrm{Y}$ \\
\hline
\end{tabular}

Source: Author's analysis of the 9- and 24-month waves of the ECLS-B.

Notes: Standard errors are displayed in parentheses and are adjusted for within-child clustering. The outcome in columns (1) and (2) is the measure of cumulative nonparental child care utilization (i.e., number of months in any non-parental arrangement). The outcome in columns (3) through (6) is the log of the Bailey Short Form Research-Edition mental test score. The instrument in columns (5) through (6) is the binary indicator for a summer assessment. See Table 4 for a list of the controls included in the models. All models include a binary indicator for wave and a control for the age at which the focal child experienced the first non-parental child care arrangement. ***, **, * indicate statistical significance at the $0.01,0.05$, and 0.10 levels, respectively. 
Table 12: Robustness Checks

\begin{tabular}{|c|c|c|}
\hline Specification & $\begin{array}{c}\text { Coefficient on } \\
\text { Current Child Care } \\
\text { (Standard Error) } \\
\text { (1) }\end{array}$ & $\begin{array}{c}\text { Coefficient on } \\
\text { Cumulative Child Care } \\
\text { (Standard Error) } \\
\text { (2) }\end{array}$ \\
\hline (1) Control for parent reports of child's health & $\begin{array}{l}-0.085^{* *} \\
(0.039)\end{array}$ & $\begin{array}{l}-0.007 * * \\
(0.003)\end{array}$ \\
\hline (2) Control for child asthma and ear infections & $\begin{array}{l}-0.095^{* *} \\
(0.041)\end{array}$ & $\begin{array}{l}-0.008 * * \\
(0.003)\end{array}$ \\
\hline (3) Control for child injuries & $\begin{array}{l}-0.091 * * \\
(0.040)\end{array}$ & $\begin{array}{l}-0.008 * * \\
(0.003)\end{array}$ \\
\hline (4) Control for self-reported maternal health & $\begin{array}{l}-0.087 * * \\
(0.040)\end{array}$ & $\begin{array}{l}-0.008^{* *} \\
(0.003)\end{array}$ \\
\hline (5) Control for maternal occupation & $\begin{array}{l}-0.094 * * \\
(0.037)\end{array}$ & $\begin{array}{l}-0.007 * * \\
(0.003)\end{array}$ \\
\hline (6) Control for January births & $\begin{array}{l}-0.091 * * \\
(0.040)\end{array}$ & $\begin{array}{l}-0.008^{* *} \\
(0.003)\end{array}$ \\
\hline (7) Control for state conditions at child's birth & $\begin{array}{l}-0.103^{*} \\
(0.062)\end{array}$ & $\begin{array}{l}-0.007 \\
(0.005)\end{array}$ \\
\hline (8) Omit children living in the South & $\begin{array}{l}-0.098^{* *} \\
(0.042)\end{array}$ & $\begin{array}{l}-0.008 * * \\
(0.004)\end{array}$ \\
\hline (9) Classify June as a non-summer month & $\begin{array}{l}-0.065^{*} \\
(0.038)\end{array}$ & $\begin{array}{l}-0.004 \\
(0.003)\end{array}$ \\
\hline (10) Omit June from the analysis & $\begin{array}{l}-0.071^{*} \\
(0.038)\end{array}$ & $\begin{array}{l}-0.005^{*} \\
(0.003)\end{array}$ \\
\hline (11) Classify Sept. as a non-summer month & $\begin{array}{l}-0.102^{* *} \\
(0.040)\end{array}$ & $\begin{array}{l}-0.010^{* * *} \\
(0.003)\end{array}$ \\
\hline (12) Omit Sept. from the analysis & $\begin{array}{l}-0.114^{* * *} \\
(0.039)\end{array}$ & $\begin{array}{l}-0.010^{* * *} \\
(0.004)\end{array}$ \\
\hline (13) Omit control for maternal employment & $\begin{array}{l}-0.132 * * \\
(0.052)\end{array}$ & $\begin{array}{l}-0.009 * * \\
(0.004)\end{array}$ \\
\hline (14) Omit control for household income & $\begin{array}{l}-0.095^{* *} \\
(0.039)\end{array}$ & $\begin{array}{l}-0.009 * * * \\
(0.003)\end{array}$ \\
\hline
\end{tabular}

Source: Author's analysis of the 9- and 24-month waves of the ECLS-B.

Notes: Standard errors are displayed in parentheses and are adjusted for within-child clustering.

The outcome in all models is the log of the Bailey Short Form Research-Edition mental test score. The instrument in all models is the binary indicator for a summer assessment. See Table 4 for a list of the controls included in the models. All models include a binary indicator for wave, and those in column (2) include a control for the age at which the focal child experienced the first non-parental child care arrangement. ***,**, * indicate statistical significance at the $0.01,0.05$, and 0.10 levels, respectively. 
Table 13: Alternative Instrument Sets and IV Estimator

\begin{tabular}{|c|c|c|c|c|c|c|}
\hline Variable & $\begin{array}{c}\text { 2SLS } \\
(1 \mathrm{~A})\end{array}$ & $\begin{array}{c}\text { LIML } \\
\text { (1B) }\end{array}$ & $\begin{array}{l}\text { 2SLS } \\
(2 A)\end{array}$ & $\begin{array}{c}\text { LIML } \\
\text { (2B) }\end{array}$ & $\begin{array}{l}\text { 2SLS } \\
(3 A)\end{array}$ & $\begin{array}{l}\text { LIML } \\
\text { (3B) }\end{array}$ \\
\hline Non-parental child care & $\begin{array}{l}-0.099 * * \\
(0.039)\end{array}$ & $\begin{array}{l}-0.112 * * \\
(0.045)\end{array}$ & $\begin{array}{l}-0.087 * * \\
(0.039)\end{array}$ & $\begin{array}{l}-0.104^{* *} \\
(0.046)\end{array}$ & $\begin{array}{l}-0.097 * * \\
(0.039)\end{array}$ & $\begin{array}{l}-0.145^{* *} \\
(0.061)\end{array}$ \\
\hline Instrument set (number) & \multicolumn{2}{|c|}{$\begin{array}{l}\text { Dummies for summer } \\
\text { assessment at 9- and } \\
\text { 24-months (2) }\end{array}$} & \multicolumn{2}{|c|}{$\begin{array}{l}\text { Dummies for June, } \\
\text { July, Aug, Sept } \\
\text { assessment (4) }\end{array}$} & \multicolumn{2}{|c|}{$\begin{array}{l}\text { Dummies for June, July, } \\
\text { Aug, Sept assessment at } \\
\text { 9- and 24-months (8) }\end{array}$} \\
\hline
\end{tabular}

Test of overidentifying restrictions: p-value

$\begin{array}{cccc}0.569 & & 0.543 & \\ Y & Y & Y & Y \\ Y & Y & Y & Y \\ Y & Y & Y & Y \\ Y & Y & Y & Y\end{array}$

cteristics

Family characteristics

Family characteristics $\times$ wave

State fixed effects with wave interactions

Source: Author's analysis of the 9- and 24-month waves of the ECLS-B.

Notes: Standard errors are displayed in parentheses and are adjusted for within-child clustering. The outcome in all models the log of the Bailey Short Form Research-

Edition mental test score. The instruments in columns (1A) and (1B) are separate binary indicators for a summer assessment in the 9- and 12-month waves. The instruments in columns (2A) and (2B) are separate binary indicators for each summer assessment month (i.e., June through September) irrespective of wave. The instruments in columns (3A) and (3B) are separate binary indicators for each summer assessment month in both the 9-and 12-month waves. The test of overidentifying restrictions is the

Wooldridge Score test. See Table 4 for a list of the controls included in the models. All models include a binary indicator for wave. All analyses are based on 10,201 children, providing 19,071 child-wave combinations. ***, **, * indicate statistical significance at the $0.01,0.05$, and 0.10 levels, respectively. 
Table 14: OLS and Instrumental Variables Estimates of the Impact of Current Informal and Formal Child Care Utilization

\begin{tabular}{|c|c|c|c|}
\hline Variable & $\begin{array}{c}\text { OLS } \\
\text { Full } \\
(1) \\
\end{array}$ & $\begin{array}{c}\text { Child FE } \\
\text { Full } \\
(2) \\
\end{array}$ & $\begin{array}{c}\text { IV } \\
\text { 2SLS } \\
(3)\end{array}$ \\
\hline Informal child care (vs. parental care) & $\begin{array}{c}0.002 \\
(0.002)\end{array}$ & $\begin{array}{c}0.006^{* *} \\
(0.003)\end{array}$ & $\begin{array}{l}-0.052 \\
(0.050)\end{array}$ \\
\hline Formal child care (vs. parental care) & $\begin{array}{l}0.004^{* *} \\
(0.002)\end{array}$ & $\begin{array}{c}0.003 \\
(0.003)\end{array}$ & $\begin{array}{l}-0.131^{* * *} \\
(0.043)\end{array}$ \\
\hline Child characteristics & $\mathrm{Y}$ & Y & $\mathrm{Y}$ \\
\hline Family characteristics & $\mathrm{Y}$ & $\mathrm{Y}$ & $\mathrm{Y}$ \\
\hline Family characteristics $\times$ wave & $\mathrm{Y}$ & $\mathrm{Y}$ & $\mathrm{Y}$ \\
\hline State fixed effects with wave interactions & $\mathrm{Y}$ & $\mathrm{N}$ & $\mathrm{Y}$ \\
\hline Quarter-of-birth & $\mathrm{N}$ & $\mathrm{N}$ & $\mathrm{N}$ \\
\hline
\end{tabular}


Table 15: Heterogeneous Effects of Current Non-Parental Child Care Utilization

\begin{tabular}{|c|c|c|c|}
\hline Demographic Sub-Group & $\begin{array}{c}\text { OLS } \\
\text { (1) }\end{array}$ & $\begin{array}{c}\text { Child FE } \\
\text { (2) }\end{array}$ & $\begin{array}{c}\text { IV 2SLS } \\
\text { (3) }\end{array}$ \\
\hline Focal child is male & $\begin{array}{c}0.004 \\
(0.002)\end{array}$ & $\begin{array}{c}0.002 \\
(0.003)\end{array}$ & $\begin{array}{l}-0.064 \\
(0.074)\end{array}$ \\
\hline Focal child is female & $\begin{array}{c}0.002 \\
(0.002)\end{array}$ & $\begin{array}{c}0.006^{*} \\
(0.003)\end{array}$ & $\begin{array}{l}-0.090 \\
(0.067)\end{array}$ \\
\hline Focal child is white & $\begin{array}{c}0.002 \\
(0.002)\end{array}$ & $\begin{array}{c}0.005 \\
(0.004)\end{array}$ & $\begin{array}{l}-0.202 * \\
(0.106)\end{array}$ \\
\hline Focal child is non-white & $\begin{array}{c}0.003 \\
(0.002)\end{array}$ & $\begin{array}{c}0.003 \\
(0.003)\end{array}$ & $\begin{array}{l}-0.018 \\
(0.038)\end{array}$ \\
\hline Mother is married & $\begin{array}{c}0.003 \\
(0.002)\end{array}$ & $\begin{array}{c}0.003 \\
(0.003)\end{array}$ & $\begin{array}{l}-0.171^{* *} \\
(0.084)\end{array}$ \\
\hline Mother is unmarried & $\begin{array}{c}0.002 \\
(0.003)\end{array}$ & $\begin{array}{c}0.007 * \\
(0.004)\end{array}$ & $\begin{array}{c}-0.034 \\
(0.077)\end{array}$ \\
\hline Mother has a high school degree or less & $\begin{array}{c}0.001 \\
(0.002)\end{array}$ & $\begin{array}{l}0.008^{* *} \\
(0.003)\end{array}$ & $\begin{array}{l}-0.180 \\
(0.122)\end{array}$ \\
\hline Mother has more than a high school degree & $\begin{array}{l}0.005^{* *} \\
(0.002)\end{array}$ & $\begin{array}{c}0.002 \\
(0.003)\end{array}$ & $\begin{array}{l}-0.072 \\
(0.059)\end{array}$ \\
\hline Mother is employed & $\begin{array}{l}-0.000 \\
(0.002)\end{array}$ & $\begin{array}{c}0.004 \\
(0.004)\end{array}$ & $\begin{array}{l}-0.139 * * * \\
(0.038)\end{array}$ \\
\hline Moth is not employed & $\begin{array}{l}0.006 * * \\
(0.002)\end{array}$ & $\begin{array}{c}0.006 \\
(0.004)\end{array}$ & $\begin{array}{l}-0.057 \\
(0.063)\end{array}$ \\
\hline Household SES is in bottom two quintiles & $\begin{array}{c}0.003 \\
(0.002)\end{array}$ & $\begin{array}{l}0.008^{* *} \\
(0.004)\end{array}$ & $\begin{array}{c}-0.024 \\
(0.045)\end{array}$ \\
\hline Household SES is in top three quintiles & $\begin{array}{c}0.002 \\
(0.002)\end{array}$ & $\begin{array}{c}0.003 \\
(0.003)\end{array}$ & $\begin{array}{l}-0.092 * * \\
(0.038)\end{array}$ \\
\hline
\end{tabular}

Source: Author's analysis of the 9- and 24-month waves of the ECLS-B.

Notes: Standard errors are displayed in parentheses and are adjusted for within-child clustering. The outcome in all models is the log of the Bailey Short Form Research-Edition mental test score. The instrument in all models the binary indicator for a summer assessment. See Table 4 for a list of the controls included in the models. All models include a binary indicator for wave.

$* * *, * *, *$ indicate statistical significance at the $0.01,0.05$, and 0.10 levels, respectively. 
Table 16: OLS, Fixed Effects, and Instrumental Variables Estimates of the Impact of Current and Cumulative Non-Parental Child Care Utilization on Motor Skills

\begin{tabular}{lccc}
\hline Variable & OLS & Child FE & IV 2SLS \\
\hline Panel A: Primary Measure & $\mathbf{( 1 )}$ & $\mathbf{( 2 )}$ & $\mathbf{( 3 )}$ \\
Non-parental child care & & & \\
& 0.002 & 0.003 & $-0.139^{* *}$ \\
Panel B: Alternative Measure & $(0.002)$ & $(0.003)$ & $(0.065)$ \\
Informal child care (vs. parental care) & & & \\
& 0.003 & 0.004 & -0.050 \\
Formal child care (vs. parental care) & $(0.002)$ & $(0.004)$ & $(0.082)$ \\
& 0.001 & 0.001 & $-0.190^{* *}$ \\
Panel C: Alternative Measure & $(0.002)$ & $(0.004)$ & $(0.082)$ \\
Cumulative child care & & & $-0.014^{* * *}$ \\
& -0.000 & $-0.001 * *$ & $(0.005)$ \\
\hline
\end{tabular}

Source: Author's analysis of the 9- and 24-month waves of the ECLS-B.

Notes: Standard errors are displayed in parentheses and are adjusted for within-child clustering. The outcome in all models is the $\log$ of the Bailey Short Form Research-Edition motor skills scale score. The instrument in all models the binary indicator for a summer assessment. See Table 4 for a list of the controls included in the models. All models include a binary indicator for wave. $* * *, * *, *$ indicate statistical significance at the $0.01,0.05$, and 0.10 levels, respectively. 


\section{Appendix Table 1: The Relationship between ECLS-B Assessment Timing and Non-Parental Child Care Utilization by Demographic Sub-Group}

\begin{tabular}{|c|c|}
\hline Demographic Sub-Group & $\begin{array}{c}\text { Coefficient on Summer } \\
\text { Assessment } \\
\text { (Standard Error) } \\
\end{array}$ \\
\hline Focal child is male & $\begin{array}{l}-0.024 * * * \\
(0.009)\end{array}$ \\
\hline Focal child is female & $\begin{array}{l}-0.031^{* * *} \\
(0.009)\end{array}$ \\
\hline Focal child is white & $\begin{array}{l}-0.028^{* * *} \\
(0.009)\end{array}$ \\
\hline Focal child is non-white & $\begin{array}{l}-0.030^{* * *} \\
(0.008)\end{array}$ \\
\hline Mother is married & $\begin{array}{l}-0.027 * * * \\
(0.008)\end{array}$ \\
\hline Mother is unmarried & $\begin{array}{l}-0.028^{* *} \\
(0.011)\end{array}$ \\
\hline Mother has a high school degree or less & $\begin{array}{l}-0.021^{* *} \\
(0.009)\end{array}$ \\
\hline Mother has more than a high school degree & $\begin{array}{l}-0.033^{* * *} \\
(0.009)\end{array}$ \\
\hline Mother is employed & $\begin{array}{l}-0.023^{* *} \\
(0.009)\end{array}$ \\
\hline Mother is not employed & $\begin{array}{l}-0.032^{* * *} \\
(0.009)\end{array}$ \\
\hline Household SES is in bottom two quintiles & $\begin{array}{l}-0.020 * * \\
(0.010)\end{array}$ \\
\hline Household SES is in top three quintiles & $\begin{array}{l}-0.032^{* * *} \\
(0.008)\end{array}$ \\
\hline Focal child is an only-child & $\begin{array}{l}-0.015 \\
(0.010)\end{array}$ \\
\hline Focal child has one or more siblings & $\begin{array}{l}-0.034^{* * *} \\
(0.008)\end{array}$ \\
\hline Household has one adult ages $18+$ & $\begin{array}{l}-0.017 \\
(0.018)\end{array}$ \\
\hline Household has two adults ages $18+$ & $\begin{array}{l}-0.025^{* * *} \\
(0.007)\end{array}$ \\
\hline Household has three or more adults ages $18^{+}$ & $\begin{array}{l}-0.039 * * * \\
(0.015)\end{array}$ \\
\hline
\end{tabular}

Source: Author's analysis of the 9- and 24-month waves of the ECLS-B.

Notes: Standard errors are displayed in parentheses and are adjusted for within-child clustering. The dependent

is a binary indicator for participation in any non-parental child care arrangement. The summer assessment variable is a binary indicator for whether a given family was interviewed and the child was assessed in the summer (i.e., June, July, August, or September) during the 9- or 24-month wave. See Table 4 for a list of the controls included in the models. All models include a binary indicator for wave. ***, **, * indicate statistical significance at the $0.01,0.05$, and 0.10 levels, respectively. 
Appendix Table 2: Summer Maternal Work Activity

\begin{tabular}{lccccc}
\hline & $\begin{array}{c}\text { Work vs. } \\
\text { No Work } \\
\text { Variable }\end{array}$ & $\begin{array}{c}\text { Part- vs. Full- } \\
\text { Time Work } \\
\mathbf{( 1 )}\end{array}$ & $\begin{array}{c}\text { Full-Time vs. } \\
\text { No Work } \\
\text { (3) }\end{array}$ & $\begin{array}{c}\text { Part-Time vs. } \\
\text { No Work } \\
\text { (4) }\end{array}$ & $\begin{array}{c}\text { Looking vs. } \\
\text { No Work }\end{array}$ \\
\hline Summer assessment & 0.000 & -0.015 & 0.001 & -0.008 & -0.011 \\
& $(0.008)$ & $(0.010)$ & $(0.008)$ & $(0.009)$ & $(0.008)$ \\
Child characteristics & & & & Y & Y \\
Family characteristics & $\mathrm{Y}$ & $\mathrm{Y}$ & $\mathrm{Y}$ & $\mathrm{Y}$ & $\mathrm{Y}$ \\
Family characteristics $\times$ wave & $\mathrm{Y}$ & $\mathrm{Y}$ & $\mathrm{Y}$ & $\mathrm{Y}$ & $\mathrm{Y}$ \\
State fixed effects with wave interactions & $\mathrm{Y}$ & $\mathrm{Y}$ & $\mathrm{Y}$ & $\mathrm{Y}$ & $\mathrm{Y}$ \\
Number of observations & 19,312 & $\mathrm{Y}$ & $\mathrm{Y}$ & 11,278 & 9,214 \\
\hline Source: Author's analysis of the 9- and 24-month waves of the ECLS-B. & & & & &
\end{tabular}

Source: Author's analysis of the 9- and 24-month waves of the ECLS-B.
Notes: Standard errors are displayed in parentheses and are adjusted for within-child clustering. The summer assessment variable is a binary indicator for whether a given family Notes: Standard errors are displayed in parentheses and are adjusted for within-child clustering. The summer assessment variable is a binary indicator for whether a given family
was interviewed and the child was assessed in the summer (i.e., June, July, August, or September) during the 9- or 24-month wave. The dependent variable in column (1) equals unity for employed mothers and zero for mothers not in the labor force. The dependent variable in column (2) equals unity for full-time working mothers (employed 35+ hours per week) and zero for part-time working mothers. The dependent variables in columns (3) and (4) equal unity for full-time and part-time working mothers, respectively, and zero for mothers not in the labor force. The dependent variable in column (5) equals unity for mothers looking for work and zero for mothers not in the labor force. See Table 4 for a list of the controls included in the models (the models presented here exclude the maternal employment controls). All models include a binary indicator for wave. ***, **, *

indicate statistical significance at the $0.01,0.05$, and 0.10 levels, respectively. 
Appendix Table 3: Summer Non-Parental Child Care Utilization by Maternal Employment Status and Place of Employment

\begin{tabular}{|c|c|c|c|}
\hline Variable & $\begin{array}{c}\text { Regression } \\
\text { Results } \\
\text { (1) } \\
\end{array}$ & $\begin{array}{c}\text { Child Care } \\
\text { Utilization Rate } \\
(2) \\
\end{array}$ & $\begin{array}{c}\text { Implied Change } \\
\text { in Utilization } \\
\text { (3) }\end{array}$ \\
\hline \multicolumn{4}{|c|}{ Panel A: By Employment Status } \\
\hline $\begin{array}{l}\text { Summer assessment } \\
\times \text { Works full-time }\end{array}$ & $\begin{array}{l}-0.023^{* *} \\
(0.010)\end{array}$ & 0.838 & $-2.7 \%$ \\
\hline$\times$ Works part-time & $\begin{array}{l}-0.023 \\
(0.017)\end{array}$ & 0.659 & $-3.5 \%$ \\
\hline$\times$ Looking for work & $\begin{array}{l}-0.061^{* *} \\
(0.025)\end{array}$ & 0.339 & $-18.0 \%$ \\
\hline$\times$ Not in labor force & $\begin{array}{l}-0.027^{* * *} \\
(0.009)\end{array}$ & 0.162 & $-16.7 \%$ \\
\hline
\end{tabular}

Panel B: By Place of Employment

Summer assessment

$$
\begin{aligned}
& \times \text { Works outside home } \\
& \times \text { Works from home } \\
& \times \text { Self-employed } \\
& \times \text { Unemployed }
\end{aligned}
$$$$
-0.010
$$

$$
\begin{aligned}
& (0.010) \\
& -0.062^{* * *} \\
& (0.022) \\
& -0.021 \\
& (0.056) \\
& -0.035^{* * *}
\end{aligned}
$$

Child characteristics

Family characteristics

Family characteristics $\times$ wave

State fixed effects with wave interactions

Number of observations

Source: Author's analysis of the 9- and 24-month waves

Notes: Standard errors are displayed in parentheses and are adjusted for within-child clustering. The summer interview variable is a binary indicator for whether a given family was interviewed and the child was assessed in the summer (i.e., June, July, August, or September) during the 9- or 24-month wave. The dependent variable in all models is a binary indicator for participation in any non-parental child care arrangement. See Table 4 for a list of the controls included in the models. All models include a binary indicator for wave. The model in Panel B replaces the controls for maternal employment status with separate dummy variables indicating the place of employment. $* * *, * *, *$ indicate statistical significance at the $0.01,0.05$, and 0.10 levels, respectively. 
Appendix Table 4: Summer Activities with the Focal Child by Maternal Employment Status and Place of Employment

\begin{tabular}{|c|c|c|c|c|c|c|c|}
\hline Variable & $\begin{array}{c}\text { Read Stories } \\
\text { Sing Songs } \\
\text { (1) }\end{array}$ & $\begin{array}{c}\text { Run } \\
\text { Errands } \\
(2)\end{array}$ & $\begin{array}{c}\text { Walk/Play } \\
\text { Yard/Park } \\
\text { (3) }\end{array}$ & $\begin{array}{l}\text { Visit } \\
\text { Zoo } \\
\text { (4) }\end{array}$ & $\begin{array}{c}\text { Visit } \\
\text { Museum } \\
\text { (5) }\end{array}$ & $\begin{array}{c}\text { Breakfast } \\
\text { Together } \\
\text { (6) }\end{array}$ & $\begin{array}{c}\text { Dinner } \\
\text { Together } \\
\text { (7) }\end{array}$ \\
\hline \multicolumn{8}{|l|}{$\begin{array}{l}\text { Panel A: By Employment Status } \\
\text { Summer assessment }\end{array}$} \\
\hline$\times$ Works full-time & $\begin{array}{c}0.017 * \\
(0.010)\end{array}$ & $\begin{array}{l}0.043^{* * *} \\
(0.013)\end{array}$ & $\begin{array}{l}0.184^{* * *} \\
(0.013)\end{array}$ & $\begin{array}{l}0.114^{* * *} \\
(0.017)\end{array}$ & $\begin{array}{l}0.036^{* * *} \\
(0.013)\end{array}$ & $\begin{array}{l}0.027^{* * *} \\
(0.009)\end{array}$ & $\begin{array}{c}0.013^{*} \\
(0.007)\end{array}$ \\
\hline$\times$ Works part-time & $\begin{array}{c}0.022 \\
(0.014)\end{array}$ & $\begin{array}{l}0.039 * * \\
(0.017)\end{array}$ & $\begin{array}{l}0.228 * * * \\
(0.017)\end{array}$ & $\begin{array}{l}0.170^{* * *} \\
(0.024)\end{array}$ & $\begin{array}{c}0.020 \\
(0.019)\end{array}$ & $\begin{array}{c}0.014 \\
(0.012)\end{array}$ & $\begin{array}{l}0.024^{* *} \\
(0.010)\end{array}$ \\
\hline$\times$ Looking for work & $\begin{array}{l}-0.022 \\
(0.018)\end{array}$ & $\begin{array}{l}0.060 * * \\
(0.026)\end{array}$ & $\begin{array}{l}0.152^{* * *} \\
(0.027)\end{array}$ & $\begin{array}{l}0.100 * * * \\
(0.038)\end{array}$ & $\begin{array}{l}0.026 \\
(0.027)\end{array}$ & $\begin{array}{c}0.016 \\
(0.018)\end{array}$ & $\begin{array}{l}0.032 * * \\
(0.013)\end{array}$ \\
\hline$\times$ Not in labor force & $\begin{array}{l}-0.003 \\
(0.009)\end{array}$ & $\begin{array}{l}0.030 * * \\
(0.012)\end{array}$ & $\begin{array}{l}0.195^{* * *} \\
(0.012)\end{array}$ & $\begin{array}{l}0.109 * * * \\
(0.016)\end{array}$ & $\begin{array}{l}0.056^{* * *} \\
(0.012)\end{array}$ & $\begin{array}{c}0.012 \\
(0.008)\end{array}$ & $\begin{array}{c}0.001 \\
(0.006)\end{array}$ \\
\hline
\end{tabular}

Panel B: By Place of Employment

Summer assessment

\begin{tabular}{|c|c|c|c|c|c|c|c|}
\hline$\times$ Works outside home & $\begin{array}{c}0.011 \\
(0.009)\end{array}$ & $\begin{array}{l}0.040 * * * \\
(0.012)\end{array}$ & $\begin{array}{l}0.190 * * * \\
(0.012)\end{array}$ & $\begin{array}{l}0.118 * * * \\
(0.016)\end{array}$ & $\begin{array}{l}0.033^{* * *} \\
(0.011)\end{array}$ & $\begin{array}{l}0.024^{* * *} \\
(0.008)\end{array}$ & $\begin{array}{r}0.012 * \\
(0.007)\end{array}$ \\
\hline$\times$ Works from home & $\begin{array}{l}0.047 * * \\
(0.020)\end{array}$ & $\begin{array}{l}0.047 * * \\
(0.023)\end{array}$ & $\begin{array}{l}0.235^{* * *} \\
(0.023)\end{array}$ & $\begin{array}{l}0.187^{* * *} \\
(0.033)\end{array}$ & $\begin{array}{c}0.031 \\
(0.028)\end{array}$ & $\begin{array}{c}0.025 \\
(0.016)\end{array}$ & $\begin{array}{l}0.032 * * * \\
(0.012)\end{array}$ \\
\hline × Self-employed & $\begin{array}{l}-0.038 \\
(0.044)\end{array}$ & $\begin{array}{l}0.017 \\
(0.055)\end{array}$ & $\begin{array}{l}0.186^{* * * *} \\
(0.056)\end{array}$ & $\begin{array}{c}0.079 \\
(0.073)\end{array}$ & $\begin{array}{l}-0.012 \\
(0.052)\end{array}$ & $\begin{array}{l}-0.056 \\
(0.038)\end{array}$ & $\begin{array}{c}0.034 \\
(0.029)\end{array}$ \\
\hline × Unemployed & $\begin{array}{l}-0.004 \\
(0.008)\end{array}$ & $\begin{array}{l}0.036 * * * \\
(0.011)\end{array}$ & $\begin{array}{l}0.189 * * * \\
(0.011)\end{array}$ & $\begin{array}{l}0.106 * * * \\
(0.015)\end{array}$ & $\begin{array}{l}0.050 * * * \\
(0.011)\end{array}$ & $\begin{array}{c}0.013 * \\
(0.007)\end{array}$ & $\begin{array}{c}0.007 \\
(0.005)\end{array}$ \\
\hline characteristics & $\mathrm{Y}$ & $\mathrm{Y}$ & $\mathrm{Y}$ & $\mathrm{Y}$ & Y & $\mathrm{Y}$ & Y \\
\hline characteristics & $\mathrm{Y}$ & $\mathrm{Y}$ & $\mathrm{Y}$ & $\mathrm{Y}$ & $\mathrm{Y}$ & $\mathrm{Y}$ & $\mathrm{Y}$ \\
\hline characteristics $\times$ wave & $\mathrm{Y}$ & $\mathrm{Y}$ & $\mathrm{Y}$ & $\mathrm{N}$ & $\mathrm{N}$ & $\mathrm{Y}$ & $\mathrm{Y}$ \\
\hline $\begin{array}{l}\text { ixed effects with wave interactions } \\
\text { me availability }\end{array}$ & $\begin{array}{c}\text { Y } \\
\text { 9-/24-months }\end{array}$ & $\begin{array}{c}\text { Y } \\
\text { 9-/24-months }\end{array}$ & $\begin{array}{c}\mathrm{Y} \\
\text { 9-/24-months }\end{array}$ & $\begin{array}{c}\mathrm{Y} \\
\text { 24-months }\end{array}$ & $\begin{array}{c}\mathrm{Y} \\
\text { 24-months }\end{array}$ & $\begin{array}{c}\mathrm{Y} \\
\text { 9-/24-months }\end{array}$ & $\frac{\mathrm{Y}}{\text { 9-/24-months }}$ \\
\hline
\end{tabular}

Outcome availability

9-/24-months

Notes: Standard errors are displayed in parentheses and are adjusted for within-child clustering. The summer interview variable is a binary indicator for whether a given family was interviewed and the child was assessed in the summer (i.e., June, July, August, or September) during the 9- or 24-month wave. All outcomes are defined as binary indicators of whether the respondent engaged in a given activity with the focal child. The outcomes in columns (1) through (3) inquire about activities engaged in everyday, columns (4) and (5) inquire about activities engaged in within the previous month; and columns (6) and (7) inquire about activities engaged in 5+ days per week. See Table 4 for a list of the controls included in the models. All models include a binary indicator for wave. The model in Panel B replaces the controls for maternal employment status with separate dummy variables indicating the place of employment. The models in columns (4) and (5) include only the state fixed effects (not the wave interactions). ***,**,* indicate statistical significance at the $0.01,0.05$, and 0.10 levels, respectively. 
Appendix Table 5: Child Characteristics by Month of ECLS-B Interview-

Comparison of Compliers and Non-Compliers

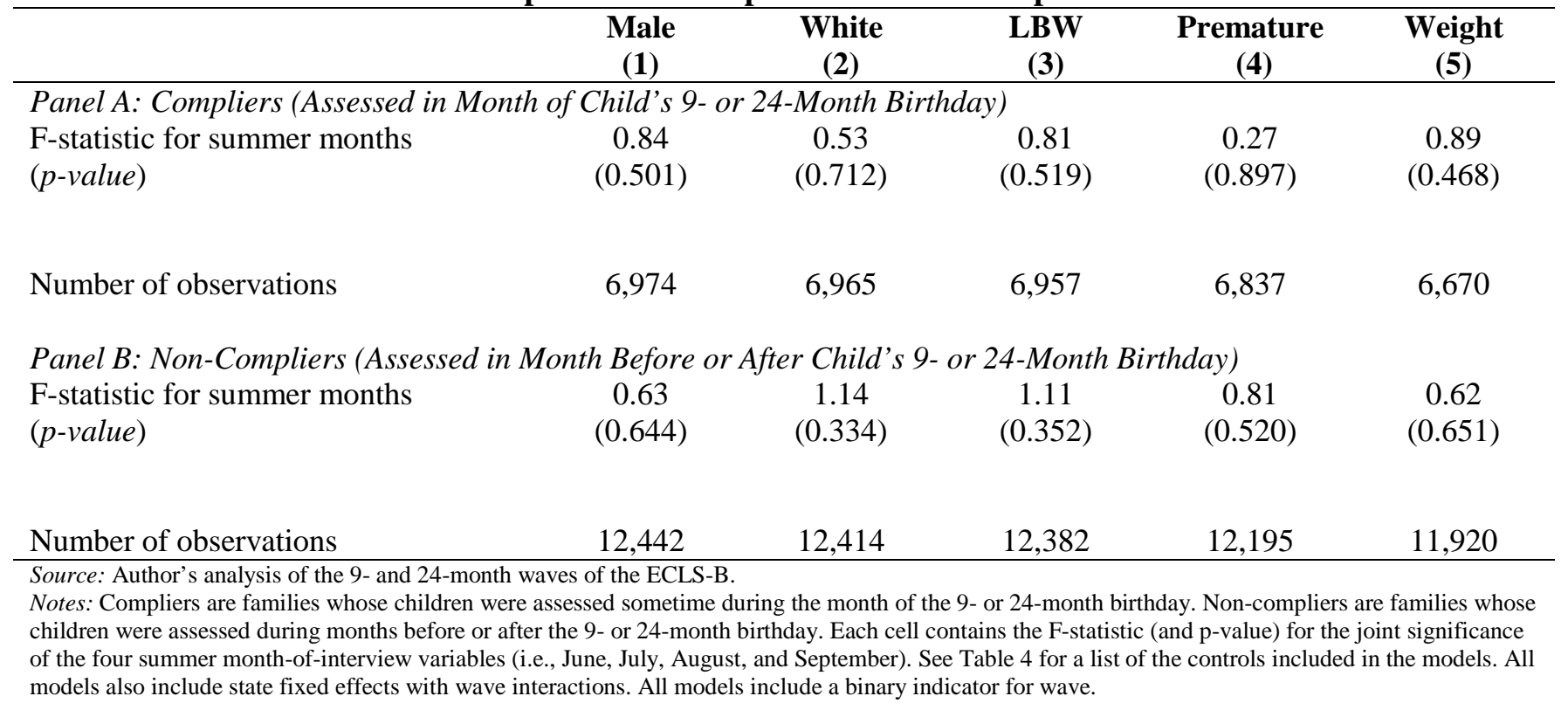


Appendix Table 6: Family Characteristics by Month of ECLS-B Interview-

Comparison of Compliers and Non-Compliers

\begin{tabular}{|c|c|c|c|c|c|}
\hline & $\begin{array}{c}\text { Never } \\
\text { Married } \\
(1)\end{array}$ & $\begin{array}{c}\text { High School } \\
\text { Drop-Out } \\
\text { (2) }\end{array}$ & $\begin{array}{c}\text { Excell/VG } \\
\text { Health } \\
\text { (3) }\end{array}$ & $\begin{array}{c}\text { Bottom SES } \\
\text { Quintile } \\
\text { (4) }\end{array}$ & $\begin{array}{c}\text { Top SES } \\
\text { Quintile } \\
\text { (5) }\end{array}$ \\
\hline \multicolumn{6}{|c|}{ Panel A: Compliers (Assessed in Month of Child's 9- or 24-Month Birthday) } \\
\hline $\begin{array}{l}\text { F-statistic for summer months } \\
\text { (p-value) }\end{array}$ & $\begin{array}{c}0.63 \\
(0.644)\end{array}$ & $\begin{array}{c}0.49 \\
(0.740)\end{array}$ & $\begin{array}{c}2.82 \\
(0.024)\end{array}$ & $\begin{array}{c}0.72 \\
(0.581)\end{array}$ & $\begin{array}{c}0.74 \\
(0.567)\end{array}$ \\
\hline Number of observations & 6,927 & 6,957 & 6,973 & 6,974 & 6,974 \\
\hline \multicolumn{6}{|c|}{ Panel B: Non-Compliers (Assessed in Month Before or After Child's 9- or 24-Month Birthday) } \\
\hline $\begin{array}{l}\text { F-statistic for summer months } \\
\text { (p-value) }\end{array}$ & $\begin{array}{c}0.76 \\
(0.554)\end{array}$ & $\begin{array}{c}1.56 \\
(0.182)\end{array}$ & $\begin{array}{c}1.62 \\
(0.167)\end{array}$ & $\begin{array}{c}1.58 \\
(0.176)\end{array}$ & $\begin{array}{c}3.17 \\
(0.013)\end{array}$ \\
\hline Number of observations & 12,288 & 12,396 & 12,441 & 12,442 & 12,442 \\
\hline
\end{tabular}

Source: Author's analysis of the 9- and 24-month waves of the ECLS-B.

Notes: Compliers are families whose children were assessed sometime during the month of the 9- or 24-month birthday. Non-compliers are families whose

children were assessed during months before or after the 9- or 24-month birthday. Each cell contains the F-statistic (and p-value) for the joint significance

of the four summer month-of-interview variables (i.e., June, July, August, and September). The outcomes in columns (1) through (3) relate to the focal

child's mother. The outcome in column (3) is a binary indicator for whether a given mother self-reports being in "excellent" or "very good" health. See

Table 4 for a list of the controls included in the models. All models also include state fixed effects with wave interactions. All models include a binary

indicator for wave. 


\section{Appendix Table 7: OLS and Instrumental Variables Estimates of the Impact}

of Relative, Non-Relative, and Center-Based Child Care Utilization

\begin{tabular}{|c|c|c|c|}
\hline Variable & $\begin{array}{l}\text { OLS } \\
\text { Full } \\
(1)\end{array}$ & $\begin{array}{c}\text { Child FE } \\
\text { Full } \\
\text { (2) } \\
\end{array}$ & $\begin{array}{c}\text { IV } \\
\text { 2SLS } \\
\text { (3) }\end{array}$ \\
\hline Relative child care (vs. parental care) & $\begin{array}{c}0.003 \\
(0.002)\end{array}$ & $\begin{array}{l}0.007^{* * *} \\
(0.003)\end{array}$ & $\begin{array}{l}-0.049 \\
(0.052)\end{array}$ \\
\hline Non-relative child care (vs. parental care) & $\begin{array}{c}0.000 \\
(0.002)\end{array}$ & $\begin{array}{l}-0.000 \\
(0.003)\end{array}$ & $\begin{array}{l}-0.155^{* * *} \\
(0.049)\end{array}$ \\
\hline Center-based child care (vs. parental care) & $\begin{array}{l}0.007^{* * *} \\
(0.002)\end{array}$ & $\begin{array}{c}0.005 \\
(0.003)\end{array}$ & $\begin{array}{l}-0.146^{* *} \\
(0.059)\end{array}$ \\
\hline Child characteristics & $\mathrm{Y}$ & $\mathrm{Y}$ & $\mathrm{Y}$ \\
\hline Family characteristics & $\mathrm{Y}$ & $\mathrm{Y}$ & Y \\
\hline Family characteristics $\times$ wave & $\mathrm{Y}$ & $\mathrm{Y}$ & $\mathrm{Y}$ \\
\hline State fixed effects with wave interactions & $\mathrm{Y}$ & $\mathrm{N}$ & $\mathrm{Y}$ \\
\hline Quarter-of-birth & $\mathrm{N}$ & $\mathrm{N}$ & $\mathrm{N}$ \\
\hline \multicolumn{4}{|c|}{$\begin{array}{l}\text { Source: Author's analysis of the 9- and 24-month waves of the ECLS-B. } \\
\text { Notes: Standard errors are displayed in parentheses and are adjusted for within-child clustering. . In columns (1) and (2), a } \\
\text { single regression of test scores is estimated on separate binary indicators of relative, non-relative, and center-based child } \\
\text { care utilization. In column (3), each cell represents a different regression of test scores on the corresponding child care } \\
\text { arrangement. Relative child care is a binary indicator that equals unity if a given child is cared for by any relative inside or } \\
\text { outside the child's home (and equals zero for participation in parent care). Non-relative child care is a binary indicator that } \\
\text { equals unity if a given child is cared for by any non-relative inside or outside the child's home (and equals zero for } \\
\text { participation in parent care). Center-based child care is a binary indicator that equals unity if a given child participates in } \\
\text { center-based care (and equals zero for participation in parent care. See Table } 4 \text { for a list of the controls included in the } \\
\text { models. All models include a binary indicator for wave. **, **, * indicate statistical significance at the } 0.01,0.05 \text {, and } 0.10 \\
\text { levels, respectively. }\end{array}$} \\
\hline
\end{tabular}




\section{Appendix 1: Summer Maternal Work Behavior and Child Activities}

As stated in the main text, Appendix Tables 2 through 4 attempt to answer two questions about children assessed in the summer and non-months of the ECLS-B. First, it is important to examine whether the rise in parent care is offset by a reduction in maternal employment or other changes in work behavior (e.g., shifting from full- to part-time work, delaying a job search, or working from home). Second, it is important to determine the types of activities in which children are engaged with parents, and in particular, whether parents make higher-quality time investments during the summer.

I first examine whether maternal work activity differs across the summer and non-summer months by regressing various measures of employment on the SUMMER dummy and the remaining controls in equation (4). All work outcomes are specified as binary indicators of different work margins. As shown in Appendix Table 2, mothers interviewed in the summer exhibit work behaviors similar to those interviewed during the non-summer months. Indeed, across all five work margins there is consistent evidence that mothers' employment does not display seasonal variation. Indeed, mothers interviewed during the summer are not less likely to do any work (versus no work), are not more likely to shift from full- to part-time work, and are not less likely to begin a job search.

Such results suggest that the largest summer-induced reductions in child care utilization may be concentrated among mothers with the most flexible work schedules. Appendix Table 3 investigates this possibility by estimating regressions of $N P$ on interactions between SUMMER and various employment schedules (Panel A) and between SUMMER and various places of employment (Panel B). Results in Panel A indicate that the summer participation "dip” is particularly large among mothers currently looking for work or not in the labor force. The regression estimates imply child care utilization reductions of 18 percent and 17 percent, respectively, for these mothers, while those working full- or part-time experience virtually no change in their summer child care use. A similar pattern emerges in Panel B: mothers with greater employment flexibility —in this case, those working from home-are more likely to stop using non-parental care in the summer compared to those working outside the home or the self-employed.

To explore the nature of children's activities during the summer, I draw on a battery of questions in the ECLS-B that inquire about the frequency with which parents and children read stories, run errands, and play in the yard; visit the zoo and museum; and eat breakfast and dinner together. Some of these activity questions are asked in both waves, while others are asked in only a single wave. All outcomes are measured as binary indicators that equal unity if a given activity occurred within the timeframe allotted in the questionnaire. For each activity, regressions are estimated on interactions between SUMMER and various employment schedules (Panel A) and between SUMMER and various places of employment (Panel B). As shown in Appendix Table 4, it is clear that parental time investments increase in the summer, regardless of mothers' employment status or place of employment. In addition, many of these investments appear to be high-quality (e.g., visiting the zoo and museums and sharing family meals). There is also evidence that the largest investments are made by mothers with the most flexible work schedules, a pattern consistent with participation “dip” discussed above. For example, mothers currently looking for work or working from home are more likely to read stories to and run errands with the focal child, visit the zoo, and have dinner as a family than mothers in other work categories. 